\title{
Analysis of Flow Induced Density Wave Oscillations in the CANDU Supercritical Water Reactor
}

\author{
Goutam Dutta $^{a, *}$, Chao Zhang ${ }^{b}$, Jin Jiang ${ }^{a_{* *}}$ \\ ${ }^{a}$ Department of Electrical and Computer Engineering, University of Western Ontario \\ London, Ontario, Canada N6A 5B9 \\ ${ }^{b}$ Department of Mechanical and Materials Engineering, University of Western Ontario \\ London, Ontario, Canada N6A 5B9
}

\begin{abstract}
In this paper, a 1-D thermal-hydraulic model, THRUST, is developed to simulate and analyze the CANDU supercritical water reactor (SCWR) from the thermodynamic point of view without considering the effect of neutronic coupling. THRUST, where a characteristic-based finite difference scheme is used, is validated against the available numerical results. The model is, then, used for the analysis of the CANDU SCWR with a primary focus to determine the conditions for potential density wave oscillations. Extensive numerical studies are performed to obtain the marginal stability boundary in the operating regime of the reactor. The effect of various parameters, such as, mass flow rate, operating pressure, axial heat flux profile, local pressure drop coefficient, and friction factor, on the stability thresholds of the reactor have been investigated.
\end{abstract}

Keywords: Supercritical water reactor, numerical thermal-hydraulic model, density wave oscillations, parametric studies

*Visiting researcher from IIITDMJ www.iiitdmj.ac.in

**Corresponding author

Email addresses: gd@iiitdmj.ac.in, gdutta@uwo.ca (Goutam Dutta),

czhang@eng.uwo.ca (Chao Zhang), jjiang@eng.uwo.ca (Jin Jiang) 


\section{Introduction}

In developing future generation nuclear technology, Canada's national program is aiming for the CANada Deuterium Uranium (CANDU) supercritical water cooled reactor (SCWR) [1], which is conceptualized and being designed with an objective to improve the thermal efficiency. The fluid in a SCWR is kept in single phase throughout the cycle to avoid the boiling crisis, such as, dry out in the reactor core and at the same time to have a compact plant design since the secondary loop and other auxiliary components, such as, steam generator, pressurizer, steam separators and dryers are eliminated. Therefore, both the cost of the initial investment for the construction of the SCWR and the need of frequent maintenance can be reduced. Despite of the similarities to the supercritical fossil power plants, the development of the CANDU SCWR poses many technical challenges. The safety of the SCWR is one of the main aspects which demands detailed study of the thermal-hydraulics (TH) of the SCWR to gain insight of the proposed SCWR technology.

The high power-to-mass flow rate ratio in SCWRs, which results in the improvement in the thermal efficiency, will cause significant reduction in the density of the water across the core similar to boiling water reactors (BWRs) and thus, strains the reactor control mechanism and increases the potential for the reactor to be susceptible to self-sustained density wave oscillations (DWOs). Several studies [2-13] confirmed the possibilities of existence of DWO for various fluids, $\mathrm{H}_{2} \mathrm{O}$ and $\mathrm{CO}_{2}$, undergoing forced or natural flow circulation under supercritical conditions. On the other hand, the DWOs, which are caused by nonlinear interactions among the various thermal and flow variables, may considerably be influenced by the nuclear coupled density and temperature reactivity feedback effects leading to power oscillations in addition to the flow oscillations. Therefore, SCWRs may share the disadvantages with BWRs, with the possibilities of dynamic flow instabilities. Sustained flow oscillations will result in oscillations in the wall temperature, which may lead to thermal fatigue of the tubes and may finally cause the breakdown of fuel elements. Moreover, the detection of DWOs is not straight forward and needs historical data of a considerable duration since DWOs are not a fast process and the frequency of oscillations is different at different operating conditions. Therefore, it is extremely important to detect and suppress such conditions during the SCWR design phase, which requires the methodology that is able to predict the instability thresholds at the given operating regime.

Due to lack of experimental data for DWOs, researchers have relied on the numerical studies. The stability for the supercritical flow of $\mathrm{H}_{2} \mathrm{O}$ in a single channel natural circulation (NC) loop was first examined by Chatoorgoon [2] using a postulated analytical methodology. The results were verified with a nonlinear 1-D TH model, known as SPORTS, which was developed by Chatoorgoon [14] for BWRs using an assumption of homogeneous flow mixture for liquid and vapor phases. In SPORTS, the property variations due to pressure were accounted for, and an implicit methodology and upwind technique for the discretization of the convective terms were 
used. But a shooting method for the solution of both steady state and transient conservation equations was employed. Further investigations for different coolants, $\mathrm{H} 2$ and $\mathrm{CO} 2$, were carried out by Chatoorgoon et al. [3, 4] using both the analytical method and SPORTS. The potential of DWOs under certain operating conditions was reported. Jain and Rizwan-uddin [6] reported DWOs for $\mathrm{CO}_{2}$ flowing in a single channel natural circulation loop using a 1-D model, FIASCO, similar to the model used in SPORTS. Gomez et al. [5] predicted DWOs for $\mathrm{H}_{2} \mathrm{O}$ flowing vertically upwards in a single channel under a given pressure drop boundary conditions (BCs) using 1-D conservation equations and two different techniques, a linearized eigenvalue approach and a time-domain model. The supercritical flows with different fluids including $\mathrm{H}_{2} \mathrm{O}$, flowing vertically upwards in a single and uniformly heated circular channel at a specified mass flow rate, were analyzed for DWOs by Ambrosini and Sharabi [7], Sharabi et al. [8] and Ambrosini [9, 12] using four different approaches: a) the linear eigenvalue approach, b) a nonlinear 1-D transient model, TRANSDIM, c) a 1-D transient model, RELAP5/MOD3.3 and d) computations fluid dynamics (CFD) approach using FLUENT. The results confirmed the existence of flow oscillations at some operating conditions and the predicted instability thresholds obtained by different approaches agreed well. T'Joen et al. [11], using the channels described by Ambrosini and Sharabi [7], predicted stability boundaries by the eigenvalue analysis of the linearized set of perturbed equations. Ampomah-Amoako and Ambrosini [13] predicted DWOs for fuel-bundle slices using another CFD program, STAR-CCM+, for supercritical water. The literature mentioned above, therefore, confirms the existence of DWOs in supercritical conditions for both NC and forced circulation $(\mathrm{FC})$ cases.

Use of linearized models through eigenvalue or Laplace transformation may help in providing the approximate stability boundaries in case of DWOs, but generally, are restricted for simplified cases and can be used as a starting point for 1-D models. 1-D nonlinear transient models may provide time response distributions of physical variables if the numerical instability issues are properly taken care of. The prediction of stability boundaries with such time-domain models, though may be more accurate, is relatively time consuming. 1-D nonlinear transient models, mentioned above, had been used to predict DWOs in BWR using the homogeneous flow assumption for the vapor and liquid phases and then, extended to SCWRs. The homogeneous flow assumption may be an added advantage for SCWRs where the fluid remains a single phase throughout. In these 1-D nonlinear transient models [5, 7-13], the dependence of properties on the pressure is generally neglected and the density changes with enthalpy only. Therefore, the momentum and energy conservation equations are decoupled and the flow, in turn, can be treated as incompressible.

Most of the instability analysis on SCWR was based on numerical studies and was restricted to hypothetical test sections. In the present research work, an equivalent circular channel is used whose hydraulic diameter is obtained from the available data related to the CANDU SCWR. One of the main objectives of the present research work is to predict the MSB for the CANDU SCWR using a single channel model. A 1-D nonlinear transient Thermal-Hydraulic 
solver Undertaking Supercritical waTer (THRUST) is developed to simulate the CANDU SCWR based on the design specification provided by Leung [15]. THRUST is developed under one dimensional flow assumption, i.e., considering the axial variation of flow and thermodynamic properties and taking the spatial mean average of field variables along the radial and azimuthal directions. THRUST developed in this work is based on the model by Dutta and Doshi [16] which was used to simulate BWRs using the homogeneous flow assumption. The model is based on the non-linear mass, momentum and energy conservation equations which are solved in the timedomain. The model also includes the thermodynamic equation of state for the supercritical water to take into account of the density variations due to pressure and temperature, and the subroutine for the supercritical water properties from the National Institute of Standards and Technology (NIST) [17] is used in this study. Because of lack of the experimental data on the instability in SCWRs, the results obtained by THRUST are validated using available data on a supercritical water flow in a channel which was numerically studied by several researchers earlier. Subsequently, THRUST is used to simulate the CANDU SCWR, and to identify the possibility of DWOs and determine its marginal stability boundary (MSB) of DWOs, if found to be present in the CANDU SCWR. The effect of various parameters expected to influence the prediction of the instability thresholds are investigated.

The paper is organized as follows: the mathematical equations used in THRUST are provided in Section 2. The validation of THRUST is carried out in Section 3. The potential of DWOs in the CANDU SCWR is analyzed in Section 4. Finally, the conclusions are given in Section 5.

\section{Mathematical details of the numerical analysis}

THRUST is developed based on the homogenous assumption. However, although the supercritical water does not experience phase change, the thermodynamic properties exhibit boiling-like drastic changes around the pseudo-critical temperature [18]. So, the non-homogeneous effect which might exist near the pseudo-critical point (PCP) is neglected in THRUST.

\subsection{Mathematical formulations of the 1-D thermal-hydraulic model}

The fundamental one-dimensional governing equations used to simulate supercritical flow in the reactor core are as follows:

$$
\frac{\partial}{\partial t}[\boldsymbol{R}]+\frac{\partial}{\partial z}[\boldsymbol{S}]=[\boldsymbol{T}]
$$

where 


$$
\begin{aligned}
& \underline{\boldsymbol{R}}=\left[\begin{array}{c}
\rho A \\
\rho A u \\
\rho A \varepsilon
\end{array}\right], \quad \underline{\underline{S}}=\left[\begin{array}{c}
\rho A u \\
A\left(\rho \kappa^{2}+p\right) \\
\rho A u e_{f}
\end{array}\right], \\
& \underline{T}=\left[\begin{array}{c}
p \frac{d A}{d z}-\tau_{w} P_{w}-\rho A g \frac{d H}{d z}-\frac{1}{2} \sum_{j=1}^{n}\left[\delta\left(z-z_{j}\right)\right] \rho_{j} u_{j}^{2} \\
q_{w}^{\prime \prime} P_{H}
\end{array}\right]
\end{aligned}
$$

and $e=e_{f}-\frac{\boldsymbol{p}}{\boldsymbol{p}}$ and $e_{f}=h+\frac{\boldsymbol{u}^{2}}{2}+g H$. The nonlinear governing equations are solved in the time-domain.

The conservative form of governing equations is first converted into the following primitive form:

$$
\frac{\partial}{\partial t}[\underline{U}]+\underline{A}(\underline{U}) \frac{\partial}{\partial z}[\boldsymbol{U}]=[\underline{D}(\underline{U})]
$$

where $\underline{\boldsymbol{U}}$ is a vector of unknown dependent variables $[W, h, p]^{T}, \underline{\underline{A}}$ is a square matrix of coefficients which are functions of $\underline{\underline{U}}$, and $\underline{\boldsymbol{D}}$ is a vector containing allowances for mass, momentum, and energy transfer across the system boundaries and between phases.

The equation of state, $p=\rho(\mathbf{v}, h)$, is used and all the thermodynamic properties change with the pressure and enthalpy along the axial direction of the channel.

The eigenvalues of matrix $\underline{\underline{A}}$ determine the mathematical class of the equations presented by Eq. (2) and it is found that all eigenvalues of $\underline{A}$ are real $(\boldsymbol{u}, \boldsymbol{u}+\boldsymbol{\alpha}, \boldsymbol{u}-\boldsymbol{\alpha})$; and hence they are classified as hyperbolic equations. Next, Eq. (2) is transformed into a characteristic form and it can be written as the following:

$$
\underline{\underline{B}} \frac{\partial}{\partial t}[\boldsymbol{U}]+\underline{\underline{A}} \underline{\underline{B}} \frac{\partial}{\partial z}[\boldsymbol{U}]=[\underline{C}]
$$

where $\underline{\underline{A}}$ is a diagonal matrix of eigenvalues of $\underline{\underline{A}}$.

After the coefficient and source terms are linearized, Eq. (3) is discretized with a characteristics-based implicit finite-difference scheme where the spatial derivative terms are approximated by a backward or forward difference depending on the sign of the characteristics. For the present case of subsonic flows $(u<a$ ), the spatial derivatives for the first two basic equations, which are characterized by $\boldsymbol{\Lambda}_{11}=\boldsymbol{u}+a>0$ and $\boldsymbol{\Lambda}_{22}=\boldsymbol{u}>0$, respectively, are 
approximated by a backward difference scheme and the third basic equation, which is characterized by $\boldsymbol{A}_{33}=\boldsymbol{u}-\boldsymbol{a}>0$, is approximated by a forward difference scheme. The resultant discretized equations are then combined together and solved iteratively with the given BCs.

When the PDEs are converted into ODEs in the Lagrangian frame of reference, there exist some mathematical restrictions in BCs associated with subsonic compressible flows [19]. In the present study, the technique in imposing the proper BCs suggested by Dutta and Doshi [20] is adopted, in which the shooting method is not needed.

\subsection{Steady state solution of the reactor core}

Steady state equations are obtained by setting $\frac{a}{\partial t}=0$ in Eq. (1), and the resultant discretized equations are as follows:

$$
\rho_{i+1} A_{i+1} u_{i+1}=\rho_{i} A_{i} u_{i}
$$

$$
\begin{aligned}
p_{i}-p_{i+1}=\frac{1}{2}( & \left.\frac{1}{A_{i}}+\frac{1}{A_{i+1}}\right)\left[\left(\rho A u^{2}\right)_{i+1}-\left(\rho A u^{2}\right)_{i}\right] \\
& +\frac{1}{2}\left[[\rho(F+g)]_{i}+[\rho(F+g)\}_{i+1}\right]\left(z_{i+1}-z_{i}\right)
\end{aligned}
$$

where $F=\frac{\tau_{w} \boldsymbol{R}_{w}}{\rho A}$

$$
\left(e_{f}\right)_{i+1}-\left(e_{f}\right)_{i}=\frac{1}{2}\left[\left(\frac{q_{w}^{\prime \prime} P_{H}}{\rho A u}\right)_{i}+\left(\frac{q_{w}^{\prime \prime} P_{H}}{\rho A u}\right)_{i+1}\right]\left(z_{i+1}-z_{i}\right)
$$

The above equations, in addition to the equation of state, are solved by using a forward marching scheme when all the inlet field variables, i.e., inlet mass flow rate, enthalpy and pressure are specified. The results obtained from the steady state model are used as the initial condition for the transient simulation.

\subsection{Unsteady solution of the reactor core}

The scheme used for the transient simulations is a different from that used in the steady state simulations. All the unknown variables are obtained once the coefficient matrix is inverted. Before the matrix inversion, the coefficient matrix and the source vector are adjusted to take care of different set of boundary conditions depending on the transient case under consideration. The pressure-velocity coupling in the transient solver is handled by simultaneously solving the nonlinearly coupled mass, momentum and energy conservation equations along with the thermodynamics equation of state. 


\subsection{Pressure drops}

The solutions of both the steady state and transient flows will provide the axial pressure distribution. Therefore, one can easily find the overall pressure drop. It is also important to determine the pressure drops due to different factors to understand the mechanisms of DWOs. The pressure gradients and the respective pressure drops due to different factors can be isolated by rearranging the axial momentum equation.

$$
\begin{gathered}
-\frac{\partial p}{\partial z}=\frac{1}{A} \frac{\partial}{\partial t}(\rho A u)+\frac{1}{A} \frac{\partial}{\partial z}\left(\rho A u^{2}\right)+\frac{\tau_{w} P_{w}}{A}+p g \frac{d H}{d z}+\frac{1}{2} \sum_{j=1}^{n}\left[\delta\left(z-z_{j}\right)\right] \rho_{j} u_{j}{ }^{2} \\
-\frac{\partial p}{\partial z}=\left(\frac{\partial p}{\partial z}\right)_{\text {tram }}+\left(\frac{\partial p}{\partial z}\right)_{a c c}+\left(\frac{\partial p}{\partial z}\right)_{\text {frie }}+\left(\frac{\partial p}{\partial z}\right)_{\text {grav }}+\left(\frac{\partial p}{\partial z}\right)_{\text {loea }}
\end{gathered}
$$

The transient pressure gradient, $\left(\frac{\partial p}{\partial_{g}}\right)_{\text {tran }}$, is defined as

$$
\left(\frac{\partial p}{\partial z}\right)_{t \operatorname{man}}=\frac{1}{A} \frac{\partial}{\partial t}(\rho A w)=\frac{1}{A} \frac{\partial}{\partial t}(W)
$$

The acceleration pressure gradient, $\left(\frac{\partial p}{\partial z}\right)_{a c c}$, is formulated as

$$
\left(\frac{\partial p}{\partial z}\right)_{a e c}=\frac{1}{A} \frac{\partial}{\partial z}\left(\rho A x^{2}\right)=\frac{1}{A} \frac{\partial}{\partial z}\left(\frac{W^{2}}{\rho A}\right)
$$

It can be simplified to the following for steady state flows in a constant area channel:

$$
\left(\frac{\partial p}{d z}\right)_{a x o}=\left[\frac{W^{2}}{A^{2}}\right] \frac{d}{d z}\left(\frac{1}{\rho}\right)
$$

The friction pressure gradient, $\left(\frac{\partial_{p}}{\partial_{z}}\right)_{f r i v}$, is defined as

$$
\left(\frac{\partial p}{\partial z}\right)_{\text {frie }}=\frac{\tau_{w} P_{W}}{A}=\left[\frac{W^{2}}{2 A^{2} D_{h}}\right]\left(\frac{f_{d}}{\rho}\right)
$$

where the Darcy-Weisbach friction factor, $f_{d}$, depends on the local Reynolds number $\left(R_{e}\right)$ and wall surface roughness ratio $\left(\frac{E}{S_{k}}\right)$. The empirical correlations provided by Churchill-Chu [21] and 
Filonenko [22] and an implicit correlation by Colebrook-white [21] are used to calculate $f_{d}$ and those relationships are given in Table 1.

The gravitation pressure gradient, $\left(\frac{\partial_{p}}{\partial_{z}}\right)_{g r a r}$, is defined as

$$
\left(\frac{\partial p}{\partial z}\right)_{g r a v}=\rho g \frac{d H}{d z}
$$

The local (irreversible) pressure gradient, $\left(\frac{\partial_{p}}{\partial_{s}}\right)_{l_{0 \sigma a l}}$, is defined as

$$
\left(\frac{\partial j}{\partial z}\right)_{l o g a l}=\frac{1}{2} \sum_{j=1}^{n}\left[\delta\left(z-z_{j}\right)\right] \rho_{j} \alpha c_{j}^{2}
$$

The local pressure gradient takes place when there is a sudden change in the crosssectional area.

Individual pressure gradient terms are then numerically integrated to obtain the respective pressure drops.

Table 1: Correlations for Darcy-Weisbach friction factor

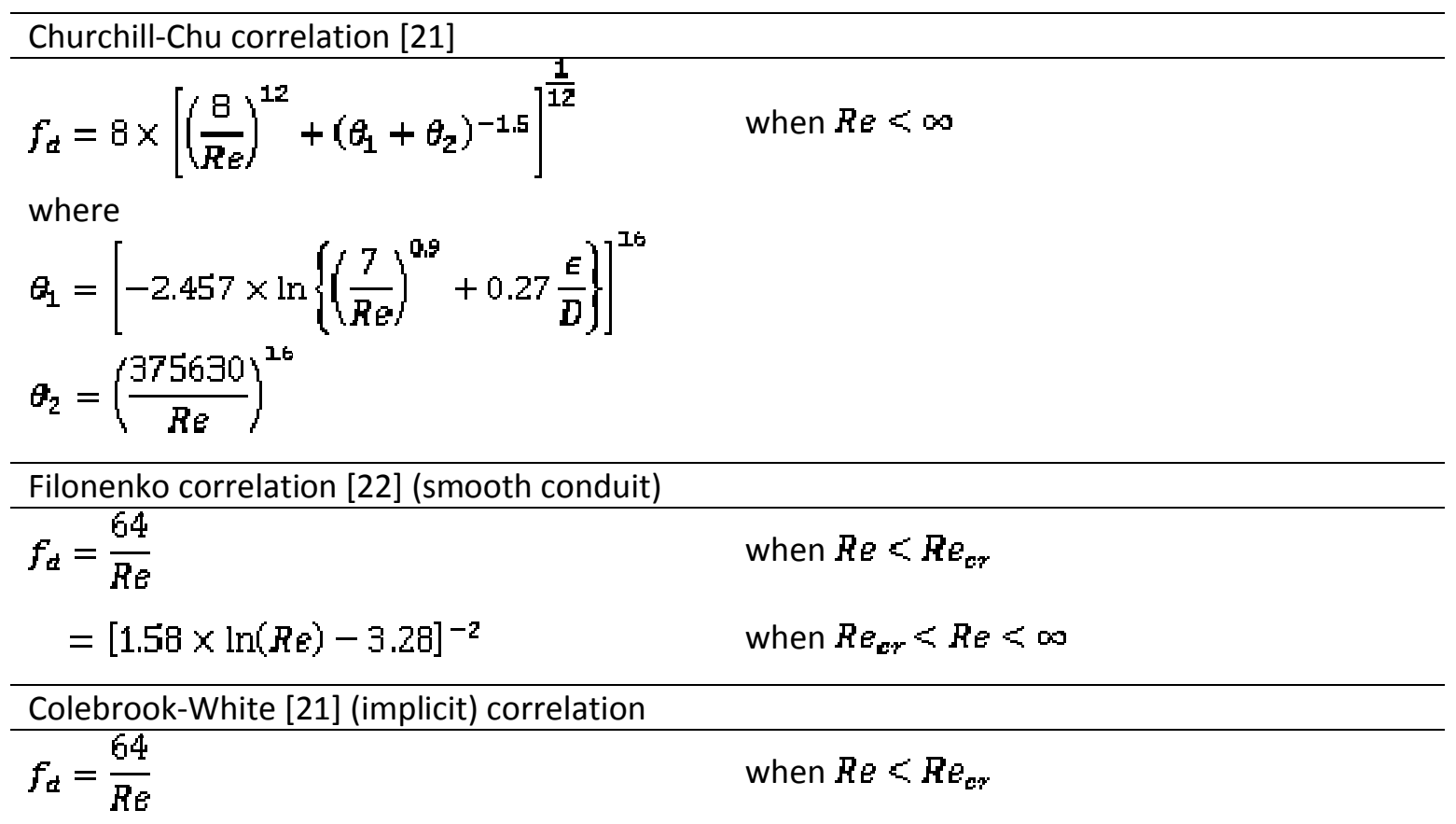


$\frac{1}{\sqrt{f_{d}}}=-2 \times \log _{10}\left(\frac{\epsilon}{3.7 D_{h}}+\frac{2.51}{R e_{\sqrt{f_{d}}}}\right) \quad$ When $\boldsymbol{R e} e_{e r}<\operatorname{Re}<\infty$

\subsection{Pseudo-critical point}

The PCP is defined as when the local temperature of the coolant reaches the pseudocritical temperature, $\boldsymbol{T}_{p e}$, which is the temperature at which the specific heat at constant pressure is the maximum. $\boldsymbol{T}_{p e}$ is determined by using the following correlation [23]:

$$
T_{p c}=274.12+114.97 \times\left(\mathrm{u}_{r}\right)-15.216 \times\left(\mathrm{p}_{r}\right)^{2}\left[{ }^{\circ} \mathrm{C}\right]
$$

where $\boldsymbol{p}_{r}$, the reduced pressure, is defined as $\boldsymbol{p}_{r}=\frac{p}{p_{c r}}$, and $p$ is the local pressure and $p_{c r}$ is the critical pressure, which is equal to $22.6 \mathrm{MPa}$ for the water.

\section{Validation of the numerical model}

The supercritical water up-flowing vertically in a single circular channel as shown in Fig. 1 is selected to validate the proposed model, THRUST. The same problem was earlier analyzed numerically by Ambrosini and Sharabi [7] and T'Joen et al. [11] to evaluate the capability of their models for the simulation of the DWOs under the supercritical condition. It is noted that the numerical results from Ambrosini and Sharabi [7] and T'Joen et al. [11] have not been verified against the experimental data. The geometrical and operating parameters of the problem under consideration are given in Table 2.

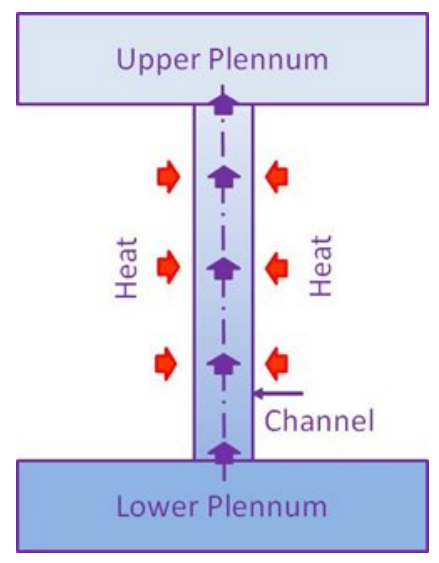

Figure 1: Schematic diagram of the single channel

Table 2: Geometrical and operating parameters of the single channel [7, 11]

\begin{tabular}{|l|l|}
\hline \multicolumn{2}{|c|}{ Geometrical Parameters } \\
\hline Length & $4.2672 \mathrm{~m}$ \\
\hline
\end{tabular}




\begin{tabular}{|l|c|}
\hline Hydraulic diameter & $3.4 \mathrm{~mm}$ \\
\hline Coolant flow area & $5.4972 \times 10^{-5} \mathrm{~m}^{2}$ \\
\hline \multicolumn{2}{|c|}{ Operating Parameters } \\
\hline Inlet temperature & $280^{\circ} \mathrm{C}$ \\
\hline Inlet pressure & $25.14 \mathrm{MPa}$ \\
\hline Exit pressure & $25.00 \mathrm{MPa}$ \\
\hline
\end{tabular}

\subsection{Comparison of steady state results}

The results from THRUST are compared with those from the 1-D models proposed by Ambrosini and Sharabi [7] (AS model) and T'Joen et al. [11] (TJ model). In the AS and TJ models, different inlet and exit orifice pressure drop coefficients were used to match the steady state axial pressure distribution obtained by them. The comparison of the steady state result at a power input of $25 \mathrm{~kW} / \mathrm{m}$ obtained by THRUST with those from the AS and TJ models is shown in Fig. 2. The comparison reveals there is a small deviation between the result from THRUST and those from the AS and TJ models when the same orifice pressure drop coefficients as those used by T'Joen et al. [11] are used in THRUST. It should be noted that in the AS model, certain inlet and exit pressure drop coefficients were chosen to match the predicted steady state axial pressure distributions. The TJ model used a different approach from the AS model and the inlet and exit pressure drop coefficients in the TJ model were also adjusted to match the steady state axial pressure distribution with that from the AS model. Therefore, the pressure drop coefficients need to be adjusted for different algorithm used in the model. With an adjustment in the inlet orifice coefficient from $\boldsymbol{k}_{i n}=27$ to $\boldsymbol{k}_{i n}=35$, the results from THRUST agree well with those from the AS and TJ models for the steady state axial distribution of various field variables including the pressure. 


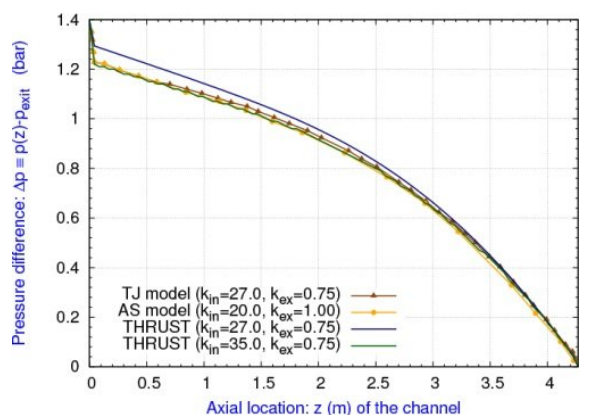

(a) Axial distribution of pressure drop

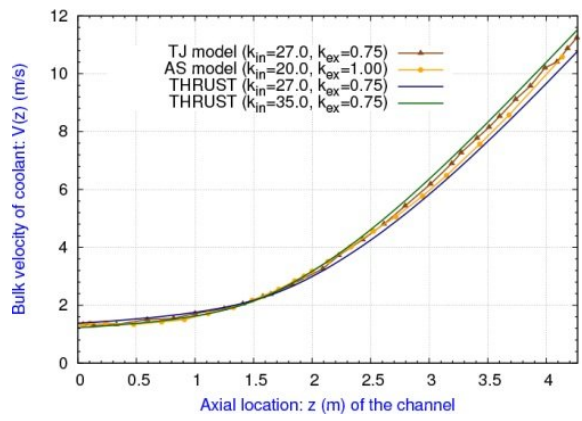

(c) Axial distribution of bulk velocity

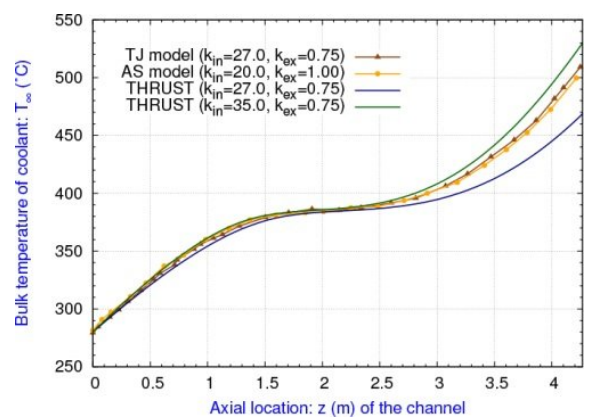

(b) Axial distribution of bulk temperature

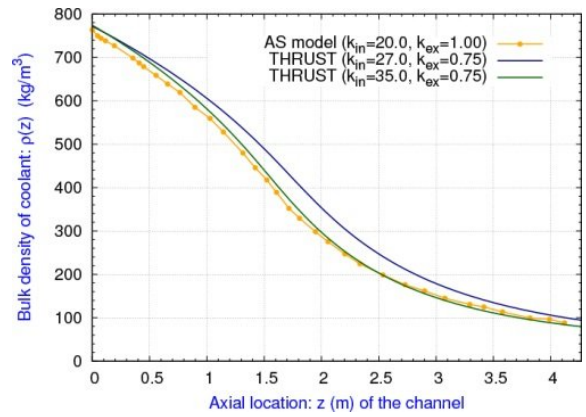

(d) Axial distribution of bulk density

Figure 2: Comparison of the steady state results for the single channel obtained by THRUST with the AS [7] and T] models [11]

\subsection{Comparison of the stability boundaries of the density wave}

The transient responses of field variables, following a perturbation from the initial steady state condition, are then obtained by THRUST to determine the stable, unstable or limiting operating point depending on whether the amplitude of the oscillations is converging, diverging or constant, respectively. The initial state corresponding to the constant amplitude oscillation represents the marginal stability point for the chosen operating condition. Many such points are then obtained with numerous permutations and combinations to find the MSB, which can differentiate the stable and unstable regimes in the operating range.

The predicted MSB can be presented in two plots: the first one is the pseudo-subcooling number, $N_{p s u b}=\left(\frac{h_{p c}-\eta_{i n}}{h_{p c}}\right)$ vs. the pseudo-phasechange number, $N_{p p c h}=\left(\frac{\dot{Q}}{W h_{p c}}\right)$, introduced by T'Joen et al. [11] and the second one is the sub-pseudo-critical number, $N_{s p c}=\left\lfloor\frac{a_{p c}}{\varepsilon_{p p c}}\right\rfloor\left(h_{p e}-h_{i m}\right)$, vs. the trans-pseudo-critical number, $N_{t p o}=\left\lfloor\frac{a_{p c}}{\varepsilon_{p, p p}}\right\rfloor\left(\frac{\dot{Q}}{W}\right)$, introduced by Ambrosini and Sharabi [7]. It can be seen that the dimensionless numbers introduced by T'Joen et al. [11] and Ambrosini and Sharabi [7] are interlinked with the scaling relationship,

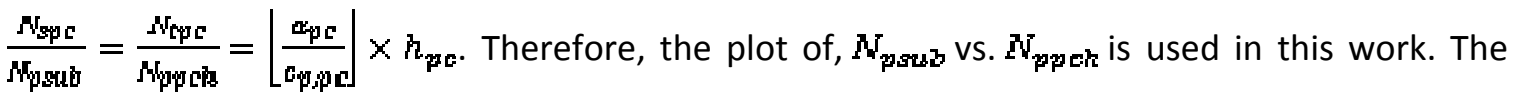
pseudo-critical properties, in the present study, are evaluated based on the exit pressure. Two 
different stability boundaries are obtained with THRUST; one with the same inlet orifice pressure coefficient as that used by $T^{\prime}$ Joen et al. [11] and another one with an adjusted orifice pressure coefficient. The predicted stability boundaries are then compared with those from the AS and TJ models, as shown in Fig. 3.

The comparison shows a better agreement with the results from the AS and TJ models for the stability boundaries using THRUST with an adjusted pressure coefficient than that without the adjusted pressure coefficient. It should be noted that the stability boundaries from the AS and TJ models were obtained using a linear approximation for the nonlinear conservation equations, which is different from the methodology adopted in THRUST. The difference in the methodologies used in different models might cause the deviations in the predicted stability boundaries. A few marginal stability points shown in Fig. 3 were obtained by Ambrosini and Sharabi [7] using a transient system code, RELAP5. The modeling techniques used in the RELAP5 are similar to those used in THRUST. Therefore, these marginal stability points are close to those from THRUST for the case when an adjusted orifice coefficient is used. There is a reasonable agreement between the present results and the available results from other researchers, thus the present model, THRUST, can be considered as a reliable tool to predict DWOs for SCWRs.

In addition to the validation of THRUST, another important observation from Fig. 3 is that the increase in the inlet orifice coefficient, from $k_{i n}=27.0$ to $k_{i n}=35.0$, in THRUST, results in an increased stable zone. This is expected since the higher inlet orifice coefficient will cause an increase in the pressure drop at the inlet section of the channel and thus, a decrease in the pressure at the exit. So, the reactor is more stable.

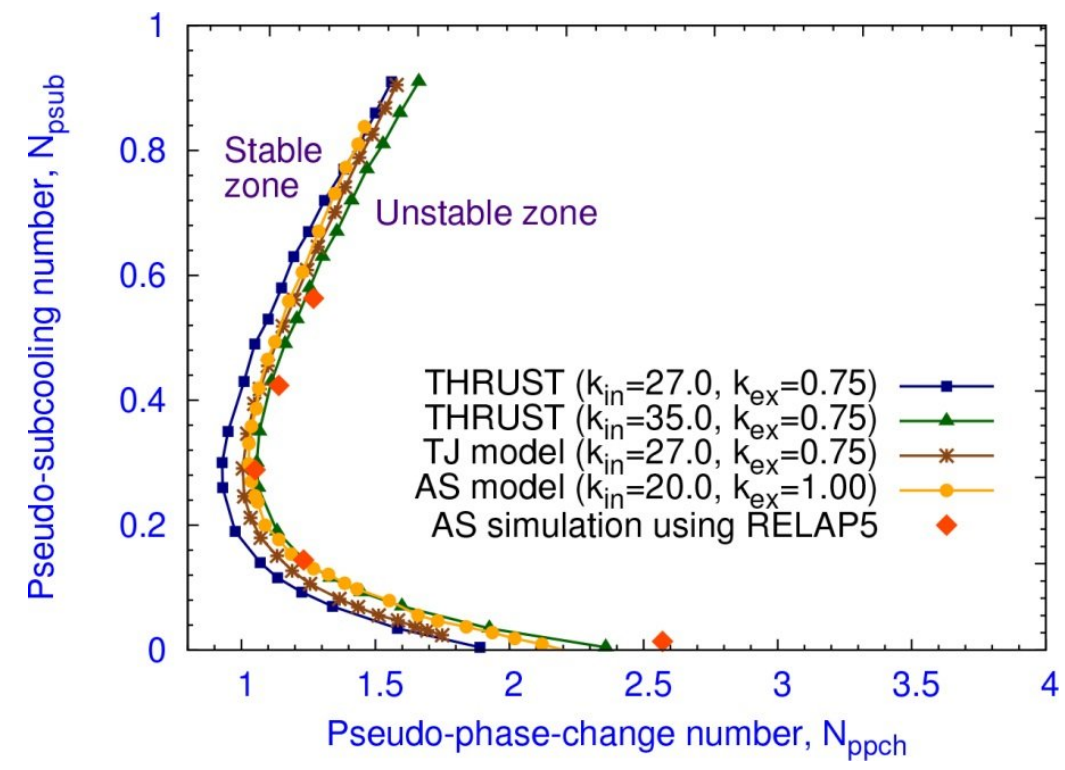

Figure 3: Comparison of stability boundaries for the single channel obtained by THRUST with AS [7] and T] models [11] 
Table 3: Operating parameters of the CANDU SCWR [15]

\begin{tabular}{|c|c|}
\hline Rated power & $2500 \mathrm{MW}$ \\
\hline Rated mass flow rate & $1320 \mathrm{~kg} / \mathrm{s}$ \\
\hline Outlet pressure & $25 \mathrm{MPa}$ \\
\hline Inlet temperature & $350^{\circ} \mathrm{C}$ \\
\hline Clad temperature & $<850^{\circ} \mathrm{C}$ \\
\hline No. of pressure tubes & 336 \\
\hline Coolant & Water \\
\hline
\end{tabular}

\section{Analysis of DWOs in the CANDU SCWR}

The configuration and operating parameters of the CANDU SCWR [15] used at the present study are given in Fig. 4(a-c) and Table 3, respectively. The CANDU SCWR is proposed to be working on the FC mode at normal operating conditions. The geometrical parameters of the individual pressure tubes given by Adouki [24] are adopted in this study and they are given in Fig. 4d and Table 4.

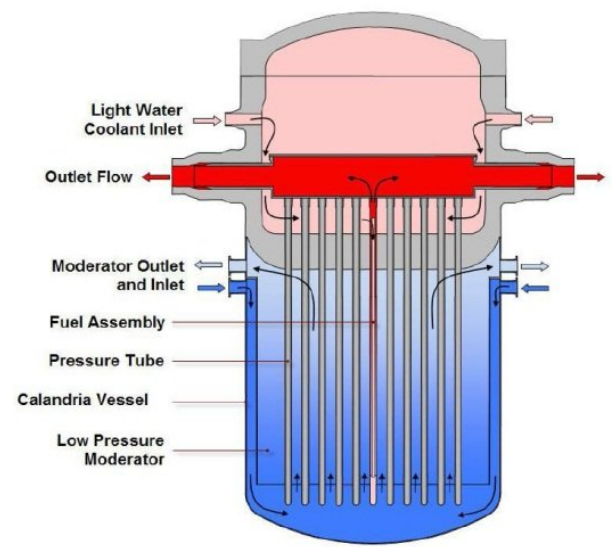

(a) Schematic diagram [15]

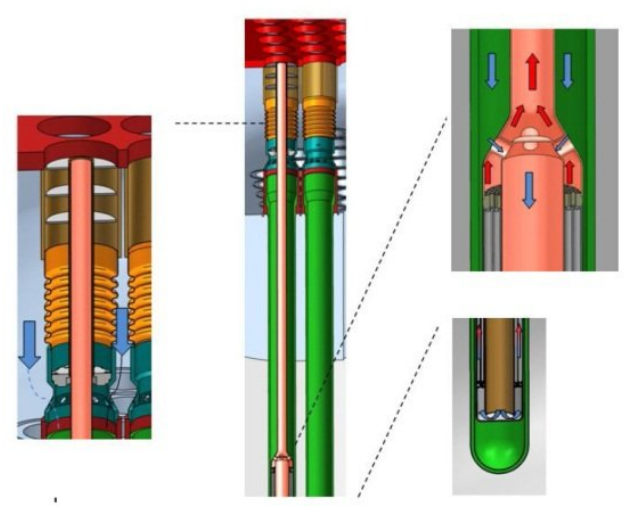

(c) Fuel channel or pressure tube configuration [15]

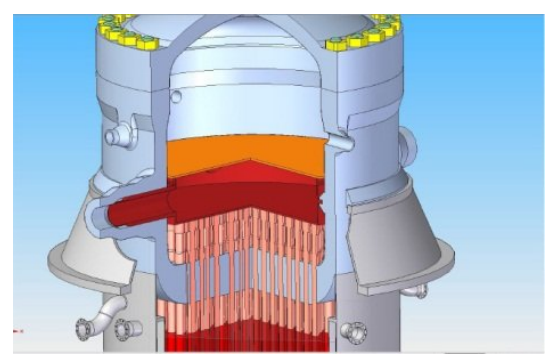

(b) Plenum configurations [15]

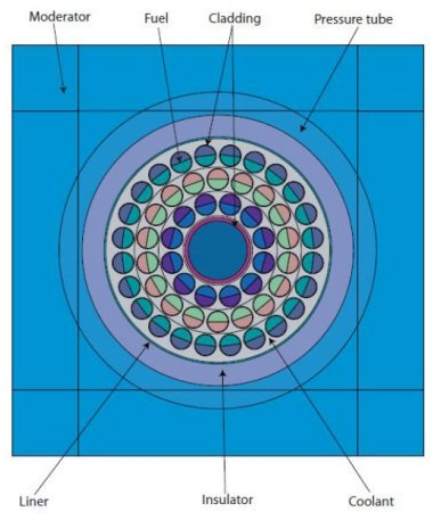

(d) Pressure tube with 54 fuel elements per bundle [24]

Figure 4: Configuration of the CANDU SCWR [15, 24] 
Table 4: Geometrical parameters of the CANDU SCWR pressure tube [24]

\begin{tabular}{|l|l|l|l|}
\hline Pitch circle radius, ring 1 & $2.8755 \mathrm{~cm}$ & Heated length & $5 \mathrm{~m}$ \\
\hline Pitch circle radius, ring 2 & $4.3305 \mathrm{~cm}$ & Pressure tube inner radius & $8.23 \mathrm{~cm}$ \\
\hline Pitch circle radius, ring 3 & $5.8000 \mathrm{~cm}$ & Pressure tube thickness & $1.4 \mathrm{~cm}$ \\
\hline Radius of central pin & $1.8 \mathrm{~cm}$ & Liner tube inner radius & $6.8 \mathrm{~cm}$ \\
\hline Outer radius of central pin cladding & $2.0 \mathrm{~cm}$ & Liner tube thickness & $0.1 \mathrm{~cm}$ \\
\hline Radius of pins in ring 1, 2 and 3 & $0.620 \mathrm{~cm}$ & Insulator inner radius & $6.9 \mathrm{~cm}$ \\
\hline Outer radius of ring 1, 2 and 3 pin cladding & $0.660 \mathrm{~cm}$ & Insulator thickness & $1.33 \mathrm{~cm}$ \\
\hline
\end{tabular}

In this study, a simplified configuration of the CANDU SCWR is modeled and its main components are shown in Fig. 5. The coolant water leaves the cold plenum, moves downwards in the central core section, takes a U-turn, and then moves vertically upwards in the annular section where the coolant gets heated from the nuclear fuel pins, and finally reaches to the hot plenum.

The convective heat transfer between the cold and hot waters is considered to be negligible, since the central core section is assumed to be insulated. The reactor core is discretized into several nodes and the conservation equations are solved numerically. The grid and time step sensitivity analysis indicated that 50 nodes for each of the downward and upward sections, and time step of $\Delta t=0.01 \mathrm{~s}$ can provide grid and time step independent results. The parameters of the CANDU SCWR used in the numerical simulation are listed in Table 5.

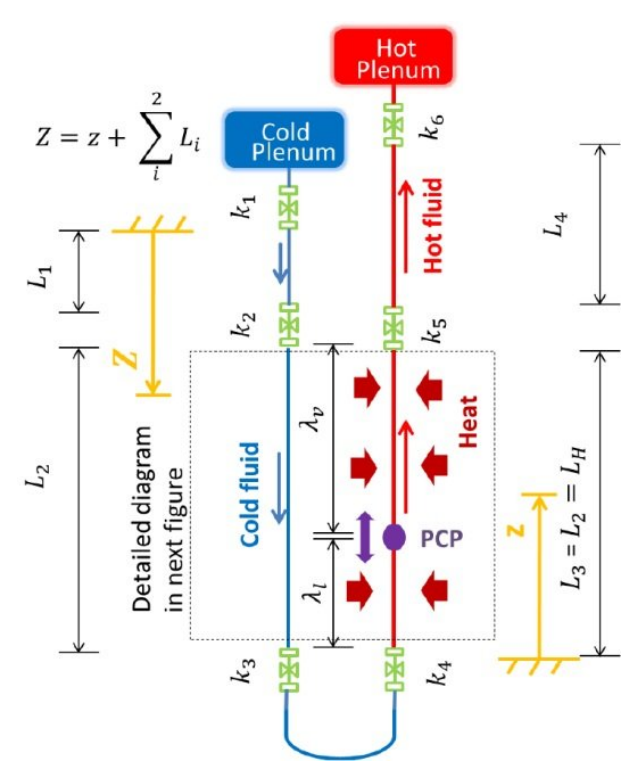

(a) Simplified schematic diagram of the coolant flow path in the pressure tube

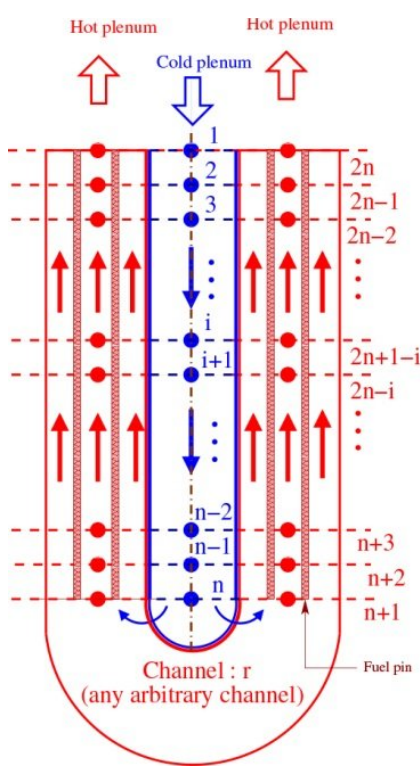

(b) Schematic diagram of the press tube

Figure 5: Simplified configuration of the CANDU SCWR 
Table 5: Parameters used in the simulation of the CANDU SCWR

\begin{tabular}{|l|l|c|}
\hline Parameters & Range/options & Nominal operating condition \\
\hline Power (\% of rated power) & $75-230 \%$ & $2226.5 \mathrm{MW}(89 \%)$ \\
\hline Mass flow rate $\%$ of rated flow rate) & $70-90 \%$ & $924 \mathrm{~kg} / \mathrm{s}(70 \%)$ \\
\hline Outlet pressure (MPa) & $23-25$ & 25 \\
\hline Inlet enthalpy (kJ/kg) & $50-2100$ & $1000\left(231^{\circ} \mathrm{C}\right)$ \\
\hline $\boldsymbol{k}_{\mathbf{1}}, \boldsymbol{k}_{\mathbf{2}}$ and $\boldsymbol{k}_{\mathbf{3}}$ (Fig. 5a) & 0 & 0 \\
\hline $\boldsymbol{k}_{\mathbf{4}}$ (Fig. 5a) & $0-5$ & 0 \\
\hline $\boldsymbol{k}_{\mathbf{5}}$ (Fig. 5a) & $0-2$ & 0 \\
\hline $\boldsymbol{k}_{\mathbf{6}}$ (Fig. 5a) & 10 & 10 \\
\hline Axial heat flux profile & Uniform and sinusoidal & Uniform \\
\hline $\begin{array}{l}\text { Friction factor } \\
\text { correlations }\end{array}$ & $\begin{array}{l}\text { Churchill-Chu, Filonenko } \\
\text { and Colebrook-White }\end{array}$ & Churchill-chu \\
\hline
\end{tabular}

\subsection{Analysis of DWOs}

The analysis of DWOs on the CANDU SCWR is performed by THRUST, under transient conditions. First, the solution at the operating point, which is obtained using THRUST under a steady state condition with the given BCs, is used as the initial conditions (ICs) for the transient simulations. The BCs are the mass flow rate, wall heat flux, enthalpy at the cold plenum (inlet) and pressure at the hot plenum (exit). The inlet pressure obtained from the steady solution, the inlet enthalpy and the exit pressure remain the same during the transient simulations. Next, a perturbation in an input variable is introduced and then, the time responses of the output variables are obtained using the transient THRUST model to determine whether the chosen operating point is stable, unstable or limiting condition. Therefore, the time dependent responses can be obtained at different operating points. The results for the nominal operating condition defined in Table 5 are shown in Fig. 6. It is revealed from Fig. 6a that the mass flow rates at the inlet and exit of the heating section oscillate at constant amplitudes and the phase lag is about $90^{\circ}$. The phase plane diagram shown in Fig. 6b, which indicates the final attainment of a close loop path for the reactor and thus, reconfirms that the CANDU SCWR at the chosen operating point is at the MSB (limit cycle). 


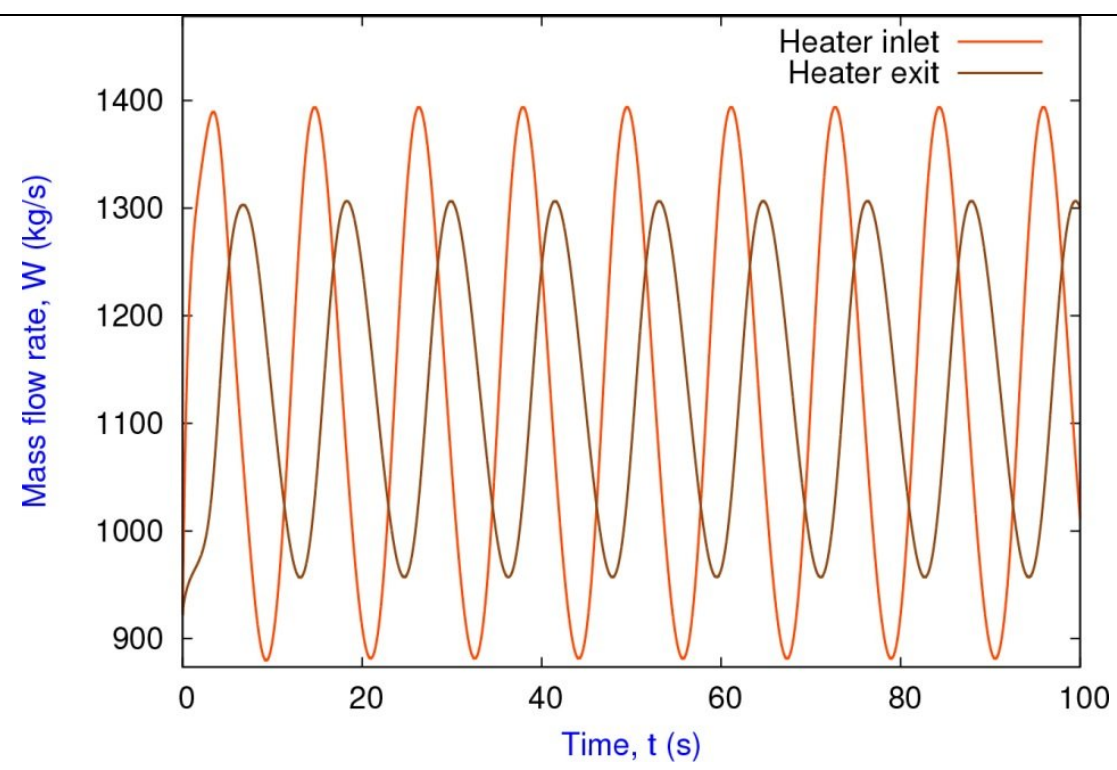

(a) Temporal variation of mass flow rates at the heater inlet and exit and their phase difference

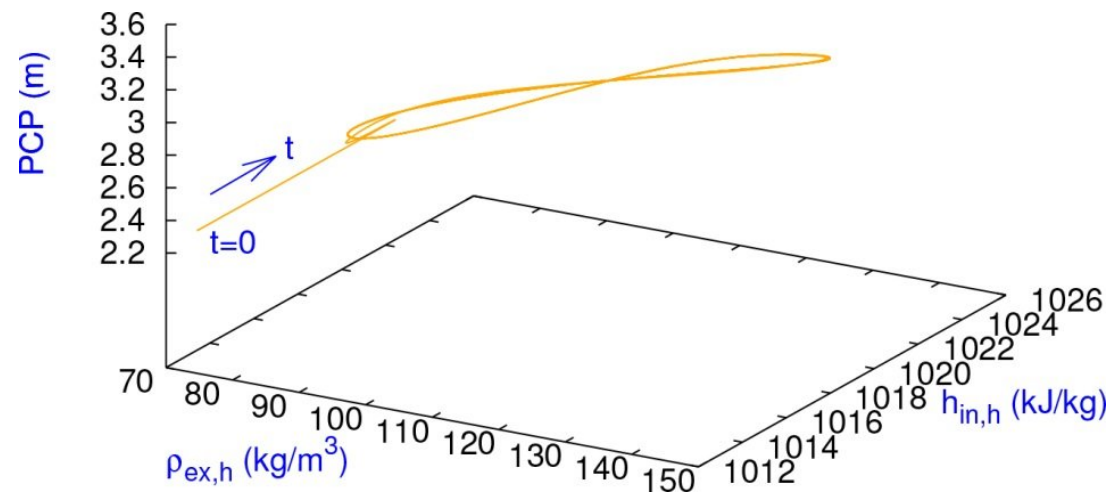

(b) Phase plane diagram of three time dependent

Figure 6: Transient behavior of the CANDU SCWR at the nominal operating condition

\subsubsection{Effect of the friction factor on the stability boundary}

It is well known that the axial pressure distribution can significantly affect the stability boundaries of the density wave. The predicted pressure drop due to friction depends on the friction factor used in the simulations. Therefore, the friction factor is an important parameter and its effect on the stability boundary needs to be examined. Three well known correlations for the friction factor are chosen in this study, the correlations by Churchill-Chu [21], Filonenko [22] and Colebrook [21]. The results are shown in Fig. 7. It can be seen that the MSB obtained with Chirchill-Chu friction factor correlation coincides with that obtained by the Colebrook correlation. The figure also shows that there is a small difference between the MSBs obtained by Filonenko friction factor correlation and the other two. Chirchill-Chu and Colebrook friction factor correlations predict larger stable zone at the lower $N_{\text {psub }}$ than that from Filonenko correlation, whereas the trend gets reversed at the higher $N_{\text {psub }}$. Since the Chirchill-Chu friction 
factor correlation is based on an explicit relationship, whereas the Colebrook friction factor correlation is based on implicit relationship, which is computationally expensive, the correlation by Churchill-Chu [21] is used for the analysis of the CANDU SCWR.

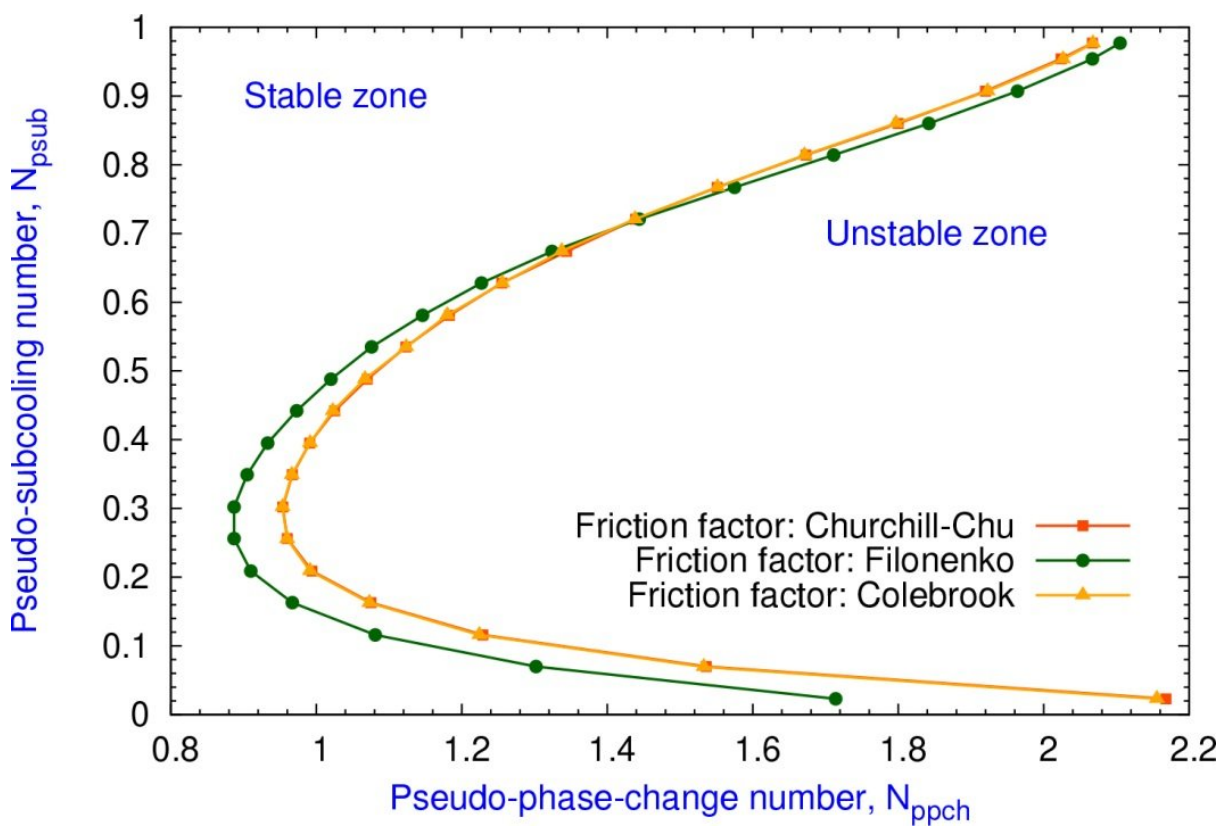

Figure 7: M arginal stability boundaries for the CANDU SCWR using three different friction factor correlations at $W=924 k_{H} / s$ and $p_{e r}=25 M P d$

\subsubsection{Effect of the system operating pressure}

The stability boundaries of the density wave are obtained for three different exit pressure conditions, $p_{a x}=25 \mathrm{MPa}, 24 \mathrm{MPa}$ and $23 \mathrm{MPa}$ and the corresponding MSBs are shown in Fig. 8. It is observed that at lower $N_{\text {prub }}$, which is the case when the temperature of the water at the channel inlet is close to the PCP, MSBs for different exit pressures almost coincide with each other. However, the difference in MSBs becomes pronounced at higher $N_{\text {psub }}$ and the stability zone gets reduced with the increase in the exit pressure. It should be noticed that the increase in the exit pressure makes a BWR more stable [25-28], but the reverse is observed for the CANDU SCWR.

To get a better insight of the DWOs, it is necessary to understand the variation of thermo-physical properties along the axial direction and their effect on various pressure drops.

Variation of thermo-physical properties in the axial direction: The comparison of the axial variations of thermo-physical properties under three different exit pressure conditions is shown in Fig. 9. Sharp changes in the thermal conductivity, specific heat, volume expansivity factor, isothermal compressibility factor, Prandtl number and acoustic speed occur near the PCP (at 
$z=2.375 m$ for $p_{a x}=25 \mathrm{MPa}, z=2.350 \mathrm{~m}$ for $p_{a x}=24 \mathrm{MPa}$ and $z=2.325 \mathrm{~m}$ for $\left.p_{a x}=23 M P_{a}\right)$. For $k, c_{p}, c_{p}, \beta_{T}$, and $P_{r}$, the peak values increase with the decrease in the exit pressure as shown in Fig. 9. It is noted that the acoustic speed $(a)$ has a minimum value near the PCP and it decreases with the decrease in the exit pressure as shown in Fig. 9d. As expected, the density and dynamic viscosity decrease in the axial direction due to the increase in the coolant temperature in the axial direction. But, the density and dynamic viscosity do not change much with the exit pressure and there are no sharp changes near the PCP for these two properties, as shown in Fig. 9(a-b). For the properties that have sharp changes near the PCP, the changes with the exit pressure are also very small outside of the PCP zone.

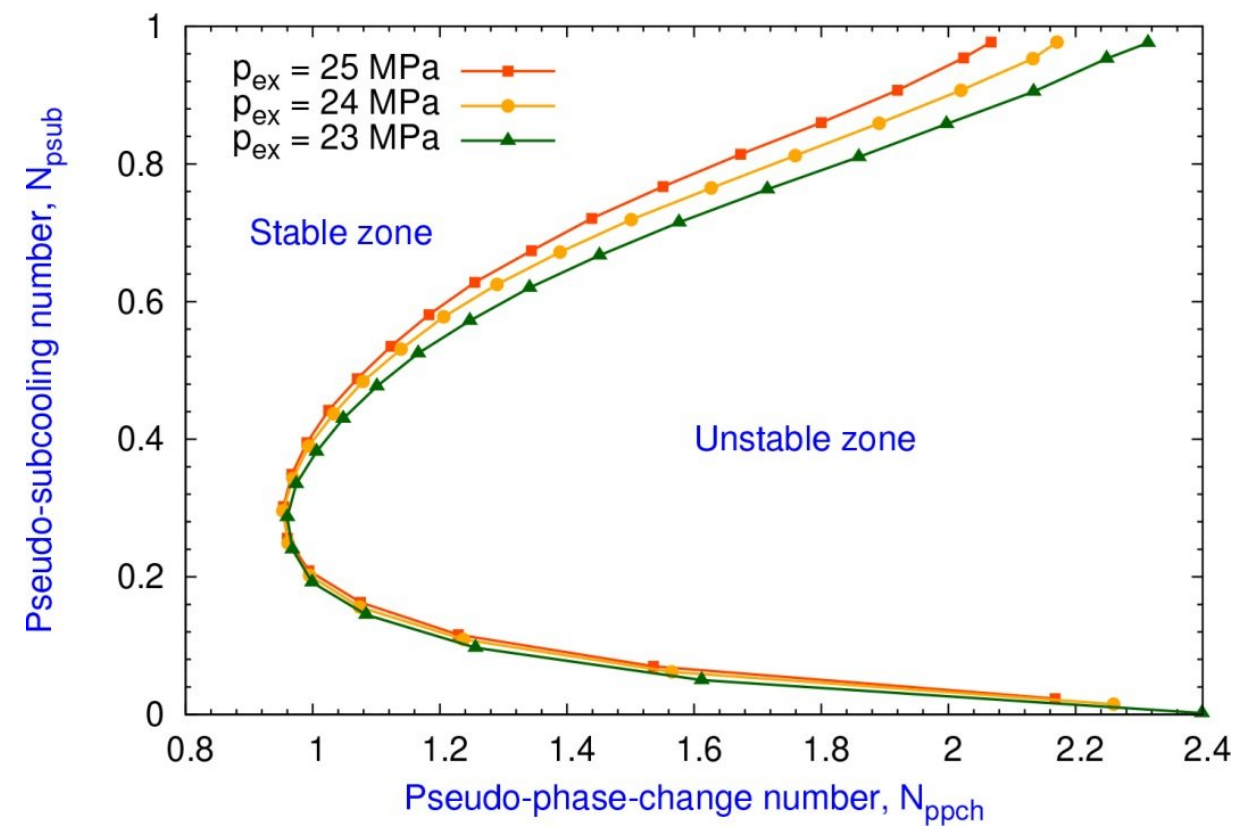

Figure 8: Marginal stability boundaries for the CANDU SCWR under three different exit pressure conditions at $W=924 \mathrm{~kg} / \mathrm{s}$

Cause for pressure drops and their effects on DWOs: The pressure gradients due to different factors along the axial direction can be evaluated based on Eqs. (5a-5h) and the results are shown in Fig. 10 for two cases, $p_{a x}=25 M P a$ and $23 M P a$. Based on Fig.8, the case with $p_{a x}=25 \mathrm{MPa}, h_{i n}=1000 \mathrm{kj}$ and $\dot{Q}=2226.5 \mathrm{MW}$ (i.e., $N_{\text {psub }}=0.53, N_{\text {ppeh }}=1.12$ ) is at the limit operating point, and the case with $p_{a x}=23 M P a$ at the same $h_{i n}$ and $\dot{Q}$ (i.e., $\left.N_{\text {psub }}=0.52, N_{p p e h}=1.14\right)$ is at the stable operating zone. The friction, acceleration, gravitation and total pressure gradients for $p_{\mathrm{ax}}=25 \mathrm{MPa}$ and $p_{\mathrm{ax}}=23 \mathrm{MPa}$ are very similar as shown in Fig. 10. More importantly, it is observed that for both cases, the pressure drop due to the gravity is significantly higher than the friction and acceleration pressure drops at the first half of the heating section of the channel where the density of the fluid is high. It gradually decreases along the axial direction as the fluid density decreases due to continuous heating 
along the axial direction. Whereas, the pressure drops due to friction and acceleration keep on increasing axially. In the second half of the channel, the friction pressure gradient overcomes the gravitation pressure gradient and the acceleration pressure gradient also becomes influential. Therefore, the friction and acceleration pressure drops are recognized as the delayed pressure drops in the SCWR and can make the reactor unstable even though their combined magnitude is much lower than the gravitation pressure drop since the delayed pressure drop is considered to be responsible for DWOs. This is different from the case of the BWR, where the type-II instability for both FC and NC modes is due to the dominant friction pressure drop [29, 30], whereas the type-I instability takes place due to the dominance of the gravitation pressure drop at the NC mode [26, 30-32]. Time-delayed transient distributions of pressure drops obtained with THRUST are shown in Fig. 11, where subscripts "I", " $\mathrm{v}$ " and " $\mathrm{t}$ " represent liquid like region (similar to BWRs) before the PCP; vapour like region (similar to BWRs) after the PCP; and total, combined effect of liquid and vapour like regions, respectively. The results indicate a phase lag between the pressure drops taking place at upstream and downstream regions of the PCP leading to self-sustained oscillations at the operating point. However, with the results shown in Figs. 9 and 10, one can interpret that the PCP in SCWRs is similar to the boiling boundary in BWRs and the friction and acceleration pressure drops in the vapor like region play, to some extent, the similar role as the two-phase pressure drop does in BWRs.

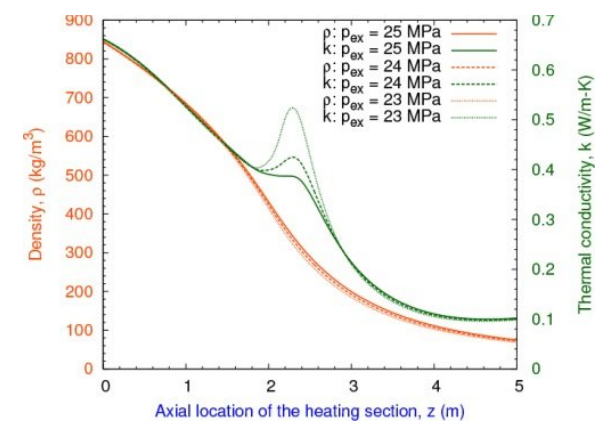

(a) $p$ and $k$

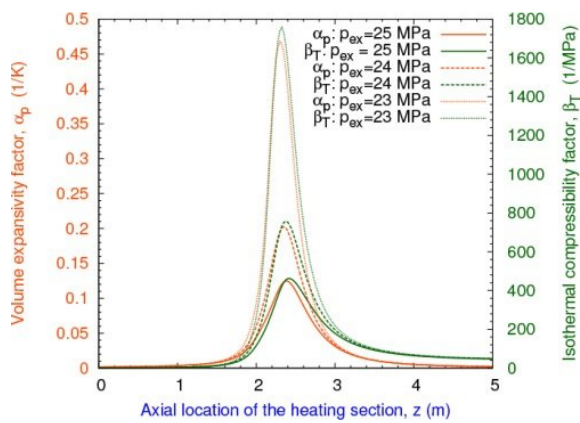

(c) $\alpha_{p}$ and $\beta_{T}$

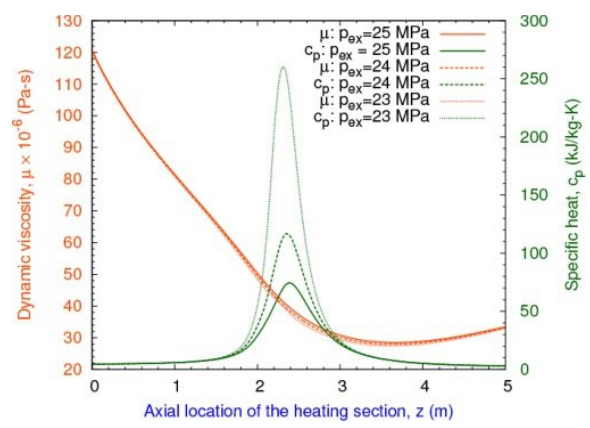

(b) $\mu$ and $c_{p}$

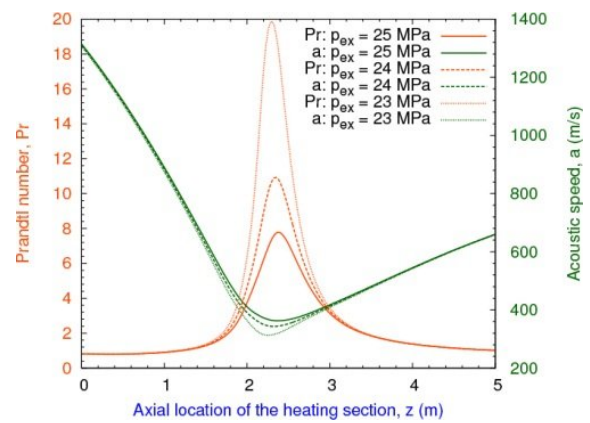

(d) $P_{\mathrm{J}}$ and $a$

Figure 9: Axial variation of thermo-physical properties in the CANDU SCWR under steady state condition at

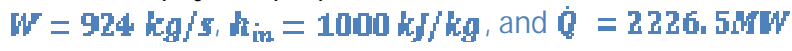




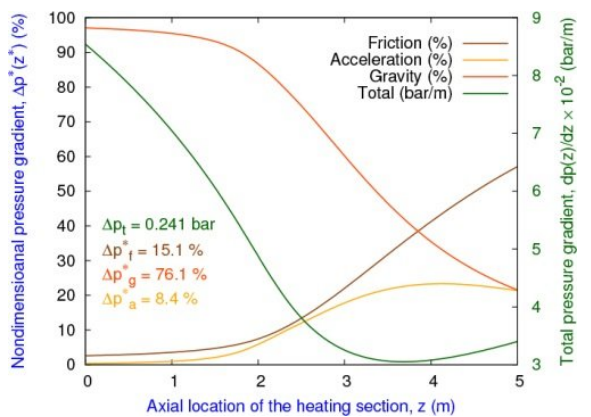

(a) $\mathrm{p}_{\mathrm{B} x \mathrm{x}}=25 \mathrm{MPa}$ (limit operating condition)

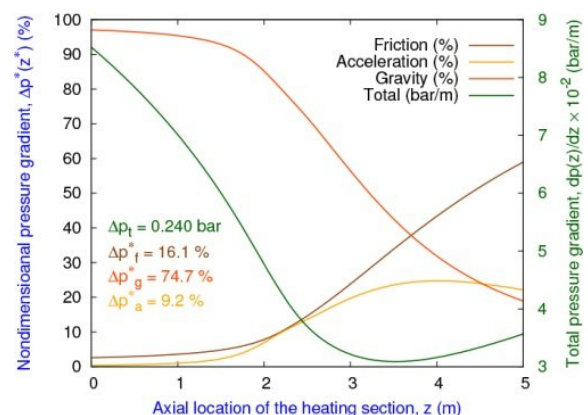

(b) $\boldsymbol{\mu}_{\mathrm{ex}}=23 \mathrm{MPa}$ (stable operating condition)

Figure 10: Axial variation of friction, acceleration, gravitation and total pressure gradients in the CANDU SCWR under steady state condition at $W=924 \mathrm{~kg} / \mathrm{s}, \mathrm{h}_{\mathrm{in}}=1000 \mathrm{~kJ} / \mathrm{kg}$, and $\mathrm{Q}=2226.5 \mathrm{WW}$

\subsubsection{Effect of the axial heat flux profile}

To understand the effect of the axial heat flux profile on the density wave MSBs, both uniform and sinusoidal heat flux profiles are used while keeping the total power the same for both cases. For the sinusoidal heat flux profile, the heat flux is zero at the inlet and exit of the channel and the maximum heat flux is at the middle of the channel. The results are shown in Fig. 12. It can be seen that the stable zone gets enlarged significantly for the case of the sinusoidal heat flux profile at low $N_{\text {psub }}$, whereas it gets reduced a little bit at high $N_{p s L b}$. Lower $N_{\text {psub }}$ means the enthalpy/temperature is higher at the channel inlet. So, the PCP will occur in the first half of the channel. The sinusoidal heat flux profile has lower heat flux in the inlet region of the channel in comparison to the uniform heat flux profile. Thus, the coolant temperature will reach to $T_{p c}$ sooner in the case of the uniform heat flux than that for the sinusoidal heat flux, i.e. the sinusoidal heat flux profile reduces the length of vapor like region. Therefore, the reactor with the sinusoidal heat flux profile is more stable. For the case of higher $N_{p s u b}$, which means the enthalpy/temperature is lower at the channel inlet, it will take longer time for the coolant temperature to reach to $\mathrm{T}_{\mathrm{pe}}$. So, the PCP will occur at the second half of the channel. The sinusoidal heat flux profile has higher heat flux at the beginning of the second half of the channel than that for the uniform heat flux profile. Therefore, the coolant temperature will reach to $\mathrm{T}_{\mathbf{p c}}$ sooner in the case of the sinusoidal heat flux than the uniform heat flux. Therefore, the sinusoidal heat flux increases the length of vapor like region and the reactor with sinusoidal heat flux becomes less stable. 


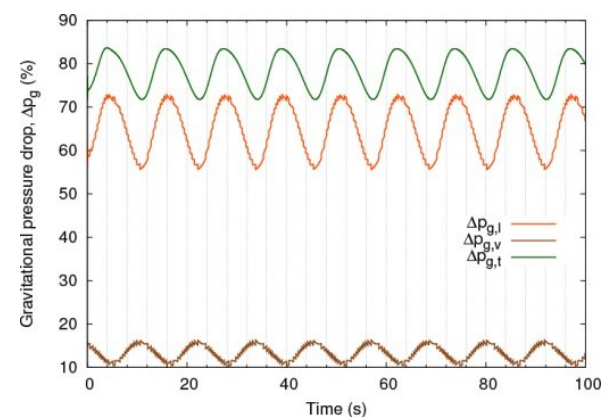

(a) Temporal variation of gravitation pressure drop

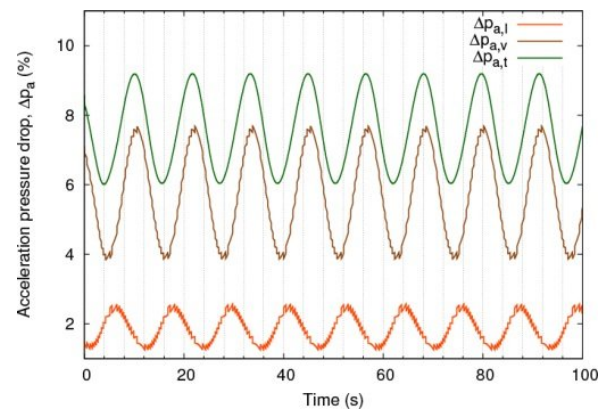

(c) Temporal variation of acceleration pressure drop

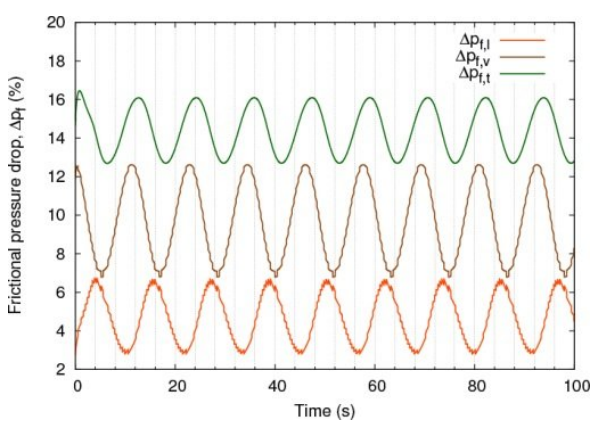

(b) Temporal variation of friction pressure drop

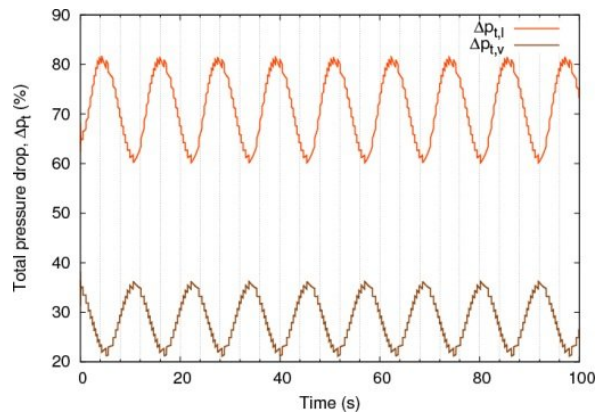

(d) Temporal variation of total pressure drop

Figure 11: Transient distributions of pressure drops in the CANDU SCWR at the nominal operating condition

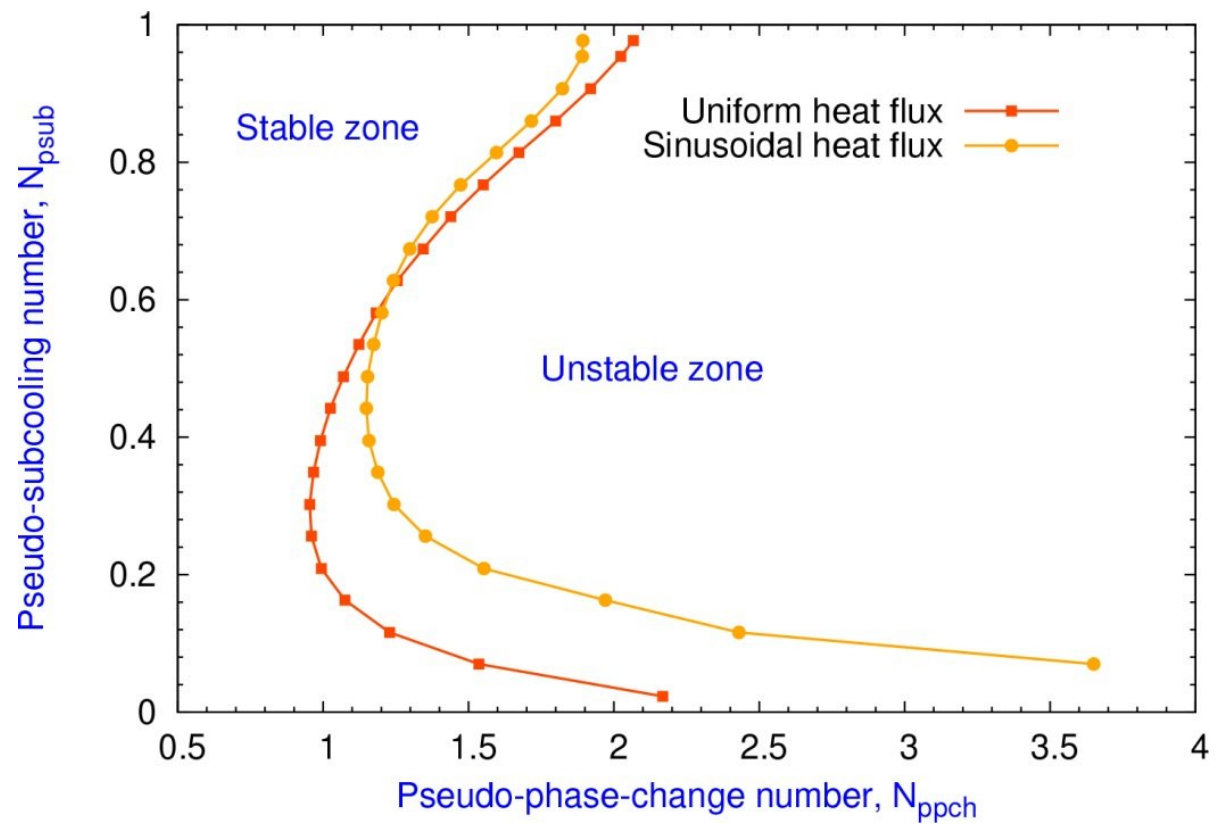

Figure 12: Marginal stability boundaries for the CANDU SCWR using two different heat flux profiles at $W=924 \mathrm{~kg} / \mathrm{s}$ and $p_{\mathrm{px}}=25 \mathrm{MPG}$ 


\subsubsection{Effect of the mass flow rate}

Three different mass flow rates are chosen to study the effect of the mass flow rate on MSBs and the results are shown in Fig. 13. Results demonstrate the monotonic enhancement of the MSB with the increase in the mass flow rate. It is because at a higher mass flow rate, more power is required to make the reactor unstable if the coolant has the same inlet enthalpy. The increase in the mass flow rate for the same power level increases the density and thereby, increases the gravitation pressure drop also. The increase in the gravitation pressure drop, in turn, reduces the combined effect of the friction and acceleration pressure drops and hence, makes the reactor more stable. The MSB for $90 \%$ of the rated mass flow rate crosses the MSB for $80 \%$ of rated mass flow rate at very low $N_{\text {psub }}$ as shown in Fig. 13 , which means that an increase in the power makes the reactor less stable at high mass flow rate when $N_{\text {psub }}$ is very low.

\subsubsection{Effect of the orifice pressure drop coefficient}

The effect of the orifice pressure drop coefficient is analyzed by varying the coefficients of the orifices located at the inlet and exit of the heating sections and the results are presented in Fig. 14. The results show that the increase in the exit orifice pressure drop coefficient makes the CANDU SCWR less stable, whereas its stability increases with the increase in the inlet orifice pressure drop coefficient. It is because the increase of the exit and the decrease of inlet orifice pressure drop coefficients directly results in an increase in the delayed pressure drop.

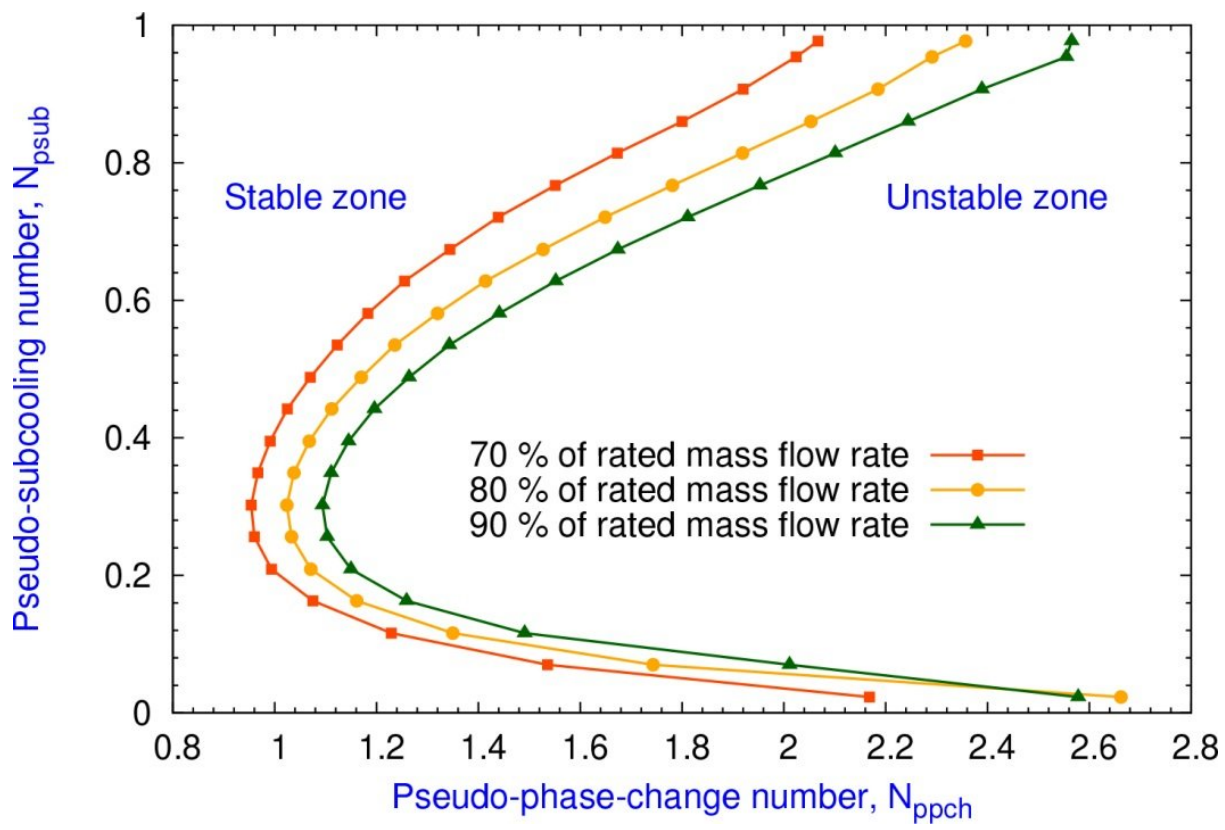

Figure 13: Marginal stability boundaries for the CANDU SCWR for three different mass flow rates at $p_{P F}=25 M P Q$ 


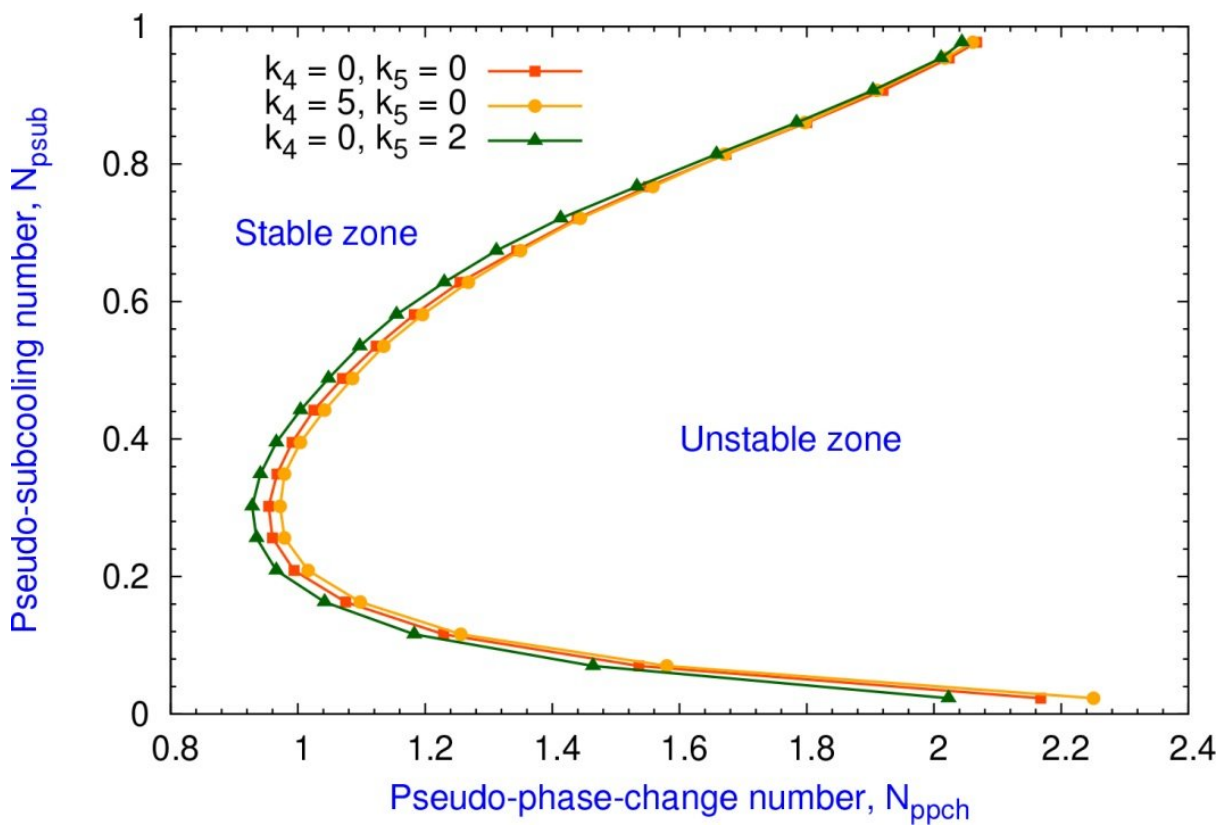

Figure 14: M arginal stability boundaries for the CANDU SCWR using three different orifice pressure drop coefficients at $W=924 \mathrm{~kg} / \mathrm{s}$ and $p_{p r}=25 \mathrm{MPa}$

\section{Conclusions}

A 1-D numerical model, THRUST, is developed to simulate TH behavior of the CANDU SCWR. The nonlinear transient solution algorithm used in THRUST is the characteristics-based implicit finite difference scheme. This model accounts for the variations of the supercritical fluid properties with the pressure as well as the temperature. THRUST is more efficient in comparison to the similar existing models, such as the one by Jain and Rizwan-uddin [6] used for the analysis of SCWR in time domain, because THRUST does not use a shooting method for the transient analysis and therefore, THRUST is computationally inexpensive for the case of parallel channel instability analysis for SCWRs that includes both in-phase and out-of-phase modes of oscillation. In addition, THRUST has the potential to take into account the neutronic reactivity feedback effects considering point reactor kinetics and analyse the instability of the CANDU SCWR accurately.

The THRUST is first validated against the available numerical results for a supercritical water channel flow undergoing DWOs. Subsequently, it is used to analyze the CANDU SCWR. The model predicts the possibility of DWOs at its normal working region under certain operating conditions and the MSB which divides stable and unstable regions can be obtained. Extensive numerical simulations have been carried out to determine the parametric effects on the MSBs and the following observations are made: 
- Increase in the power, keeping other operating parameters the same, mono- tonically enhances the possibility of DWOs.

- High power to mass flow rate ratio can make the CANDU SCWR less stable.

- For the same power to mass flow rate ratio, the reactor can be less stable at a lower flow rate. At the rated mass flow rate, the CANDU SCWR will mostly be stable unless it operates at significant higher power than its rated value.

- For the same power and other operating conditions, the reactor becomes less stable with the increase of the inlet water temperature for the relatively cold coolant and the reverse happens for very hot coolant entering the reactor channel.

- The above observations agree well with the previous experience related to FC BWR cases where type-II DWOs have been observed.

- At a supercritical condition, the increase in the operating pressure can make the reactor less stable which is oppose for BWRs.

\section{Acknowledgement}

The authors gratefully acknowledge NSERC, NRCan and the AECL Gen-IV Energy Technologies Program for providing the financial support in carrying out the above research work on the CANDU SCWR, and SHARCNET for the permission to use the computational facility.

\section{References}

[1] US DOE, NERAC, and GIF. A technology roadmap for generation IV nuclear energy systems. Technical report, 2002.

[2] V. Chatoorgoon. Stability of supercritical fluid flow in a single-channel natural-convection loop. International Journal of Heat and Mass Transfer, 44:1963-1972, 2001.

[3] V. Chatoorgoon, A. Voodi, and D. Fraser. The stability boundary for supercritical flow in natural convection loops Part I: $\mathrm{H}_{2} \mathrm{O}$ studies. Nuclear Engineering and Design, 235(24):25702580, December 2005. ISSN 00295493.

[4] V. Chatoorgoon, A. Voodi, and D. Fraser. The stability boundary for supercritical flow in natural convection loops Part II: $\mathrm{CO}_{2}$ and $\mathrm{H}_{2}$. Nuclear Engineering and Design, 235(24):25702580, December 2005. ISSN 00295493.

[5] T. O. G'omez, A. Class, R. T. Lahey, and T. Schulenberg. Stability analysis of a uniformly heated channel with supercritical water. Nuclear Engineering and Design, 238(8):1930-1939, August 2008. ISSN 00295493. 
[6] P. K. Jain and Rizwan-uddin. Numerical analysis of supercritical flow instabilities in a natural circulation loop. Nuclear Engineering and Design, 238(8):1947-1957, August 2008. ISSN 00295493.

[7] W. Ambrosini and M. Sharabi. Dimensionless parameters in stability anal- ysis of heated channels with fluids at supercritical pressures. Nuclear Engineering and Design, 238(8):19171929, August 2008. ISSN 00295493.

[8] M. B. Sharabi, W. Ambrosini, and S. He. Prediction of unstable behaviour in a heated channel with water at supercritical pressure by CFD models. Annals of Nuclear Energy, 35(5):767-782, May 2008. ISSN 03064549.

[9] W. Ambrosini. Discussion on the stability of heated channels with different fluids at supercritical pressures. Nuclear Engineering and Design, 239(12): 2952-2963, December 2009. ISSN 00295493.

[10] J. Zhao, C. P. Tso, and K. J. Tseng. SCWR single channel stability analysis using a response matrix method. Nuclear Engineering and Design, 241(7): 2528-2535, July 2011. ISSN 00295493.

[11] C. T'Joen, L. Gilli, and M. Rohde. Sensitivity analysis of numerically determined linear stability boundaries of a supercritical heated channel. Nuclear Engineering and Design, 241:3879-3889, July 2011. ISSN 00295493.

[12] W. Ambrosini. Assessment of flow stability boundaries in a heated channel with different fluids at supercritical pressure. Annals of Nuclear Energy, 38(2-3):615-627, February 2011. ISSN 03064549.

[13] E. Ampomah-Amoako and W. Ambrosini. Developing a CFD methodology for the analysis of flow stability in heated channels with fluids at supercritical pressures. Annals of Nuclear Energy, 54:251-262, April 2013. ISSN 03064549.

[14] V. Chatoorgoon. A simple thermalhydraulic stability code. Nuclear Engineering and Design, 93:51-67, 1986.

[15] L. Leung. Canada's supercritical water-cooled reactor concept. In Informa-tion Exchange Meeting Phase-II NSERC/NRCan/AECL Gen-IV Energy Technologies Program, 2013.

[16] G. Dutta and J. B Doshi. Nonlinear analysis of nuclear coupled density wave instability in time domain for a boiling water reactor core undergoing core-wide and regional modes of oscillations. Progress in Nuclear Energy, 51(8):769-787, November 2009. ISSN 01491970.

[17] National Institute of Standards and Technology. URL http://www.nist. gov/. 
[18] J. Zhao, C. P. Tso and K. J. Tseng. Nonhomogeneous-nonequilibrium two-phase-flow model for nuclear reactor single-channel stability analysis. Nuclear Technology, 180:78-88, October 2012.

[19] C. B. Laney. Computational Gas Dynamics. Cambridge University Press, United Kingdom, first edition, 1998.

[20] G. Dutta and J. B. Doshi. A Numerical Algorithm for the Solution of Simultaneous Nonlinear Equations to Simulate Instability in Nuclear Reactor and Its Analysis. In B. Murgante et al., editor, Lecture Notes in Computer Science, volume 6783, pages 695-710. Springer-Verlag Berlin Heidelberg, iccsa 2011 edition, 2011.

[21] X. D. Fang, Y. Xu, and Z. R. Zhou. New correlations of single-phase friction factor for turbulent pipe flow and evaluation of existing single- phase friction factor correlations. Nuclear Engineering and Design, 241(3): 897-902, March 2011. ISSN 00295493.

[22] M. A. Kedzierski and M. S. Kim. Single pahse heat transfer and pressure drop charecteristics of an integral spine fin within an annulus. Technical report, U.S. Department of Energy, Office of Building Technology, Building Equipment Division, Washington, DC, 1994. URL http://fire.nist.gov/bfrlpubs/build94/PDF/b94049.pdf.

[23] J. R. Howell and S. H. Lee. Convective Heat Transfer in the Entrance Region of a Vertical Tube for Water near the Thermodynamic Critical Point. International Journal of Heat and Mass Transfer, 42:1177-1187, 1999.

[24] P. Adouki. Neutronics-thermalhydraulics coupling in a CANDU SCWR. Ph.d. thesis, University of Montreal, 2012. URL http://publications. polymtl.ca/946/1/2012_PierreAdouki.pdf.

[25] J. A. Boure, A. E. Bergles, and L. S. Tong. Review of Two-phase Flow Instability. Nuclear Engineering and Design, 25:165-192, 1973.

[26] D. D. B. V. Bragt and T. H. J. J. V. D. Hagen. Stability of Natural Circulation Boiling Water Reactors: Part II-Parametric Study of Coupled Neutronic-Thermohydraulic Stability. Nuclear Technology, 121:52-62, 1998.

[27] M. Furuya, F. Inada, and T.H.J.J. van der Hagen. Flashing-induced density wave oscillations in a natural circulation BWRmechanism of instability and stability map. Nuclear Engineering and Design, 235(15):1557-1569, July 2005. ISSN 00295493.

[28] C. L. Hsieh, H. T. Lin, J. R. Wang, S. C. Chiang, T. L. Weng, and C. Shih. BWR Parametric Sensitivity Effect of Regional Mode Instability on Stability Boundary. Journal of Power and Energy Systems, 2(1):361-370, 2008. ISSN 1881-3062. 
[29] J. M. Leuba and J. M. Rey. Coupled Thermohydraulic-Neutronic Instabilities in Boiling Water Nuclear Reactors: A Review of the State of the Art. Nuclear Engineering and Design, 145(1993):97-111, 2008.

[30] G. Dutta and J. B. Doshi. A Characteristics-Based Implicit Finite-Difference Scheme for the Analysis of Instability in Water Cooled Reactors. Nuclear Engineering and Technology, 40(6):477-488, 2008. ISSN 1738-5733.

[31] Rizwan-uddin and J. Dorning. Nonlinear Dynamics of Two-phase Flow in Multiple Parallel Heated Channels. Two-phase Flow and Heat Transfer ASME, 197:63-72, 1992.

[32] D. D. B. V. Bragt and T. H. J. J. V. D. Hagen. Stability of Natural Circulation Boiling Water Reactors: Part I-Description Stability Model and Theoretical Analysis in Terms of Dimensional Groups. Nuclear Technology, 121:40-51, 1998.

\section{Nomenclature}

\begin{tabular}{|c|c|}
\hline $\boldsymbol{A}$ & Area, $\mathrm{m}^{2}$ \\
\hline$a$ & Acoustic speed, $\mathrm{m} / \mathrm{s}$ \\
\hline$\varepsilon_{p}$ & Specific heat at constant pressure, $\mathrm{J} / \mathrm{kgK}$ \\
\hline$e$ & Specific internal energy, $\mathrm{J} / \mathrm{kg}$ \\
\hline$e_{f}$ & Specific flow energy, J/kg \\
\hline$D$ & Diameter of a tube, $\mathrm{m}$ \\
\hline$D_{h}$ & Hydraulic diameter, $\mathrm{m}$ \\
\hline$f_{d}$ & Darcy-Weisbach friction factor \\
\hline$g$ & Gravitational acceleration, $\mathrm{m} / \mathrm{s}^{2}$ \\
\hline$H$ & Height, $\mathrm{m}$ \\
\hline$h$ & Specific enthalpy, J/kg \\
\hline$k$ & Thermal conductivity, $\mathrm{W} / \mathrm{mK}$ \\
\hline$k_{i}$ & $\mathrm{i}^{\text {th }}$ orifice pressure drop coefficient \\
\hline$P$ & Perimeter, $\mathrm{m}$ \\
\hline$P_{H}$ & Heated perimeter, $\mathrm{m}$ \\
\hline$P_{W}$ & Wetted perimeter, $\mathrm{m}$ \\
\hline$p$ & Pressure, $\mathrm{Pa}$ \\
\hline $\operatorname{pr}$ & Reduced pressure \\
\hline$\dot{Q}$ & Power, W \\
\hline$q^{\prime \prime}$ & Heat flux, W/m² \\
\hline$T$ & Temperature, ${ }^{\circ} \mathrm{C}$ \\
\hline$t$ & Time, $\mathrm{s}$ \\
\hline $\boldsymbol{u}$ & Axial velocity, $\mathrm{m} / \mathrm{s}$ \\
\hline$V$ & Bulk velocity, $\mathrm{m} / \mathrm{s}$ \\
\hline$W$ & Mass flow rate, $\mathrm{kg} / \mathrm{s}$ \\
\hline
\end{tabular}




\begin{tabular}{|l|l|}
\hline$z$ & Axial location, $\mathrm{m}$ \\
\hline$z_{j}$ & Axial location where geometrical discontinuity takes place, $\mathrm{m}$ \\
\hline
\end{tabular}




\section{Greek Letters}

\begin{tabular}{|l|l|}
\hline $\boldsymbol{\alpha}_{\boldsymbol{p}}$ & Volume expansivity factor, 1/K \\
\hline $\boldsymbol{\beta}_{T}$ & Isothermal compressibility factor, 1/Pa \\
\hline $\boldsymbol{A}$ & Difference \\
\hline $\boldsymbol{\delta}$ & Dirac-delta operator \\
\hline $\boldsymbol{\epsilon}$ & Surface roughness height, $\mathrm{m}$ \\
\hline $\boldsymbol{\lambda}$ & Pseudo-critical boundary from the inlet of heater section, $\mathrm{m}$ \\
\hline$\lambda_{\boldsymbol{l}}$ & Liquid like region in the heater section, $\mathrm{m}$ \\
\hline $\boldsymbol{\lambda}_{\boldsymbol{v}}$ & Vapour like region in the heater section, $\mathrm{m}$ \\
\hline $\boldsymbol{\mu}$ & Dynamic viscosity, $\mathrm{Pa} \mathrm{s}$ \\
\hline$\tau_{w}$ & Wall shear stress, $\mathrm{N} / \mathrm{m}^{2}$ \\
\hline $\boldsymbol{\rho}$ & Density of a fluid, $\mathrm{kg} / \mathrm{m}^{3}$ \\
\hline
\end{tabular}

\section{Subscripts}

\begin{tabular}{|l|l|}
\hline$a, a c c$ & Acceleration \\
\hline \multicolumn{1}{|c|}{$\boldsymbol{c r}$} & Critical condition \\
\hline $\boldsymbol{e x}$ & Exit \\
\hline $\boldsymbol{f , f r i c}$ & Friction \\
\hline $\boldsymbol{g}, \boldsymbol{g r a v}$ & Gravitation \\
\hline $\boldsymbol{h}$ & Heater \\
\hline $\boldsymbol{i n}$ & Inlet \\
\hline $\boldsymbol{l}$ & Liquid like region \\
\hline locai & Local \\
\hline $\boldsymbol{p c}$ & Pseudo-critical condition \\
\hline $\boldsymbol{t}$ & Total \\
\hline $\boldsymbol{t r a n}$ & Transient \\
\hline $\boldsymbol{v}$ & Vapour like region \\
\hline $\mathbf{w}$ & Wall \\
\hline
\end{tabular}


Dimensionless Numbers

\begin{tabular}{|c|c|}
\hline $\operatorname{Re}$ & Reynolds number, $\frac{\rho V D}{\mu}$ \\
\hline $\mathrm{Pr}$ & Prandtl number, $\frac{\mu c_{\mathrm{p}}}{k}$ \\
\hline$\Delta p_{f}^{*}$ & Nondimensional friction pressure gradient, $\frac{\left(\frac{d p}{d z}\right)_{F}}{\left(\frac{\partial p}{d z}\right)_{\mathrm{r}}}$ \\
\hline$\Delta p_{c}^{*}$ & Nondimensional friction pressure gradient, $\frac{\left(\frac{\partial p}{d z}\right)_{a}}{\left(\frac{\partial p}{d z}\right)_{r}}$ \\
\hline$\Delta p_{g}^{*}$ & Nondimensional friction pressure gradient, $\frac{\left(\frac{d p}{d z}\right)_{g}}{\left(\frac{\partial p q}{d z}\right)_{\mathrm{r}}}$ \\
\hline$N_{\text {psub }}$ & Pseudo-subcooling number, $\frac{k_{p c}-k_{\text {in }}}{h_{p c}}$ \\
\hline$N_{p p c h}$ & Pseudo-phase-change number, $\frac{\dot{Q}}{w h_{p c}}$ \\
\hline$N_{s p e}$ & Sub-pseudo-critical number, $\left[\frac{\alpha_{p c}}{a_{p p c}}\right]\left(h_{p c}-h_{i n}\right)$ \\
\hline$N_{t p p}$ & Trans-pseudo-critical number, $\frac{\alpha_{p \mathrm{pc}}}{\sigma_{p, p \mathrm{p}}} \mid\left(\frac{\dot{Q}}{W}\right)$ \\
\hline
\end{tabular}

Acronyms

\begin{tabular}{|l|l|}
\hline BC & Boundary condition \\
\hline BWR & Boiling water reactor \\
\hline CANDU & CANada Deuterium Uranium \\
\hline CFD & Computational fluid dynamics \\
\hline DWO & Density wave oscillation \\
\hline FC & Forced circulation \\
\hline IC & Initial condition \\
\hline MSB & Marginal stability boundary \\
\hline NC & Natural circulation \\
\hline PCP & Pseud-critical-point \\
\hline SCWR & Supercritical water reactor \\
\hline TH & Thermal-Hydraulic \\
\hline THRUST & Thermal-Hydraulic solveR Undertaking Supercritical waTer \\
\hline
\end{tabular}




\section{List of Figures}

Figure 1: Schematic diagram of the single channel

Figure 2: Comparison of the steady state results for the single channel obtained by THRUST with the AS [7] and TJ models [11]

Figure 3: Comparison of stability boundaries for the single channel obtained by THRUST with AS [7] and TJ models [11]

Figure 4: Configuration of the CANDU SCWR $[15,24]$

Figure 5: Simplified configuration of the CANDU SCWR

Figure 6: Transient behavior of the CANDU SCWR at the nominal operating condition

Figure 7: Marginal stability boundaries for the CANDU SCWR using three different friction factor correlations at $\mathrm{W}=924 \mathrm{~kg} / \mathrm{s}$ and $\mathrm{p}_{0 \mathrm{x}}=25 \mathrm{MPa}$

Figure 8: Marginal stability boundaries for the CANDU SCWR under three different exit pressure conditions at $W=924 \mathrm{~kg} / \mathrm{s}$

Figure 9: Axial variation of thermo-physical properties in the CANDU SCWR under steady state condition at $W=924 \mathrm{~kg} / \mathrm{s}, \boldsymbol{h}_{\text {in }}=1000 \mathrm{~kJ} / \mathrm{kg}$, and $\dot{\boldsymbol{Q}}=2226.5 \mathrm{MW}$

Figure 10: Axial variation of friction, acceleration, gravitation and total pressure gradients in the CANDU SCWR under steady state condition at $W=924 \mathrm{~kg} / \mathrm{s}, h_{\text {in }}=1000 \mathrm{~kJ} / \mathrm{kg}$, and $\bar{Q}=2226.5 \mathrm{MW}$

Figure 11: Transient distributions of pressure drops in the CANDU SCWR at the nominal operating condition

Figure 12: Marginal stability boundaries for the CANDU SCWR using two different heat flux profiles at $W=924 \mathrm{~kg} / \mathrm{s}$ and $p_{e x}=25 \mathrm{MPa}$

Figure 13: Marginal stability boundaries for the CANDU SCWR for three different mass flow rates at $p_{\text {ex }}=25 \mathrm{MPa}$

Figure 14: Marginal stability boundaries for the CANDU SCWR using three different orifice pressure drop coefficients at $W=924 \mathrm{~kg} / \mathrm{s}$ and $\mathrm{p}_{\mathrm{ox}}=25 \mathrm{MPa}$

\section{List of Tables}

Table 1: Correlations for Darcy-Weisbach friction factor

Table 2: Geometrical and operating parameters of the single channel $[7,11]$

Table 3: Operating parameters of the CANDU SCWR [15]

Table 4: Geometrical parameters of the CANDU SCWR pressure tube [24]

Table 5: Parameters used in the simulation of the CANDU SCWR 